\title{
Damage identification and seismic vulnerability assessment of a historic masonry chimney
}

\author{
Maria-Giovanna Masciotta ${ }^{1,}$, Luís F. Ramos ${ }^{1}$, Paulo B. Lourenço ${ }^{1}$, Marcello Vasta ${ }^{2}$ \\ 1 ISISE, University of Minho, Department of Civil Engineering, Campus de Azurém, Guimarães, Portugal \\ 2 University "G. d'Annunzio", Department of Engineering and Geology, Pescara, Italy
}

\author{
Article history \\ Received August, 1 2016; accepted April 7, 2017. \\ Subject classification: \\ Operational modal analysis, Damage identification, Power spectral densities, Seismic vulnerability assessment, Historic \\ masonry chimney.
}

\begin{abstract}
The present paper deals with the dynamic characterisation of a historical masonry chimney aimed at identifying the structural damage and assessing its seismic performance. The structure was severely damaged by a lightning accident and in-depth repair works were executed to re-instate its sound configuration. The case study is fully detailed, including the aspects of survey, inspection, diagnosis, and evolution of the dynamic properties of the system throughout the structural intervention. Considering the explicit dependence of the power spectral densities of measured nodal processes on their frequency content, a spectrum-driven algorithm is used to detect and locate the damage. The paper shows that the eigenparameters obtained from the decomposition of the response power spectrum matrix are sensitive to system's changes caused by evolutionary damage scenarios, thereby resulting excellent indicators for assessing both the presence and position of structural vulnerabilities. The results are compared with the ones from other modal-based damage identification methods and the strengths/limitations of the tools currently available in literature are extensively discussed. Finally, based on the crack pattern surveyed before the repair works, the weakest links of the chimney are identified and the most meaningful collapse mechanisms are analysed to verify the seismic capacity of the structure. According to the results of the kinematic analysis, the chimney does withstand the maximum site peak ground acceleration.
\end{abstract}

\section{Introduction}

During their life span, structures are susceptible to damage whether due to exogenous causes, i.e. service loads, environmental and accidental actions, or to endogenous causes, such as geometrical defects, material degradation, loss of load-bearing capacity of structural members, excessive deformations and fatigue. The recurrence of such events may adversely affect the structural integrity and compromise the long- term performance of the system. Real-time analyses and condition-based structural assessments are then necessary to prevent unexpected failures, to undertake appropriate corrective actions in due time and to mitigate the risk of damage from earthquakes in areas characterized by high seismic hazard.

The use of structural health monitoring (SHM), including vibration-based damage identification methods (VBDIMs), plays a primary role within this context as these tools allow to track and keep under control the system's health over time and to detect any possible change due to onset of damage. Among all VBDIMs, the ones combining frequencies, mode shapes and/or modal curvatures are often used for both detecting and locating damage. These methods stem from the consideration that modal parameters are inherent properties of the structure, viz. a sort of 'fingerprints'. Thus, any alteration in the global dynamic behaviour of the system does not depend on external forces and loads, but it is only related to changes in the physical properties and/or boundary conditions of the system itself. This provides a warning in the presence of damage. Hence the necessity to integrate SHM techniques with reliable dynamic-based damage identification methods able to spot the most vulnerable areas and address the application of localized experimental tests. Having a rapid condition screening of the structural health and identifying the damage at the earliest possible stage are issues of great importance in all engineering fields, but they become particularly crucial when dealing with the vulnerability assessment of heritage and strategic civil structures. All this explains the unceasing interest of the scientific community in the field of damage identification. In this regard, several techniques have been 
proposed over time: from traditional modal-based methods [Pandey et al. 1991, Dong et al. 1994, Brincker et al. 1995, Abdel Wahab and De Roeck 1999, Kim and Stubbs 2013] to model-based techniques like the FE Model Updating [Reynders et al. 2010, Gentile and Saisi 2007], from stochastic methods based on statistical properties of random signals [Liberatore and Carman 2004, Fang and Perera 2009] to more modern approaches, such as wavelet analysis transform [Gentile and Messina 2003], neural network and genetic algorithm [Vakil et al. 2008]. A review of all techniques developed hitherto falls outside the scope of the present paper and the reader is referred to existing state-of-art papers (e.g. [Doebling et al. 1996, Doebling et al. 1998, Carden and Fanning 2004, Sohn et al. 2004, Yan et al. 2007, Fan and Qiao 2010]) for this purpose. However, it is worth noting that none of the methods currently available seems to be universally efficient and only a few references are dedicated to the damage identification of historic masonry constructions [Ramos 2007, Ramos et al. 2010, De Matteis et al. 2012, Masciotta 2015, Masciotta et al. 2017].

The first aim of the present paper is to present a damage identification method recently validated by the authors [Masciotta et al. 2017, Masciotta et al. 2016], and its application to a real historic structure. The proposed approach belongs to the category of modal-based damage identification techniques and relies on spectral analysis methods, viz. methods that exploit the second order properties of the vibration characteristics of a structure to estimate its dynamic properties and identify the damage. The basic concept underlying this approach is that the eigenparameters extracted from the decomposition of the system's output power spectrum matrix can allow to detect, locate and qualitatively assess the damage. The second aim of the paper is to provide a quantitative assessment of the seismic vulnerability of the structure under analysis by identifying the most likely collapse mechanisms. Object of study is a historic masonry chimney that was struck by lightning and needed urgent remedial measures. After a brief description of the case study (Section 2), the dynamics of the system is investigated both before and after the occurrence of damage and the evolution of the modal features throughout the rehabilitation works is presented (Section 3). Next, the theoretical framework of the spectrum-driven approach is outlined along with the derivation of the spectral damage index (Section 4). The method is applied to identify the structural damage of the chimney according to an inverse formulation and the results are compared with the ones obtained from other modal-based damage identification methods (Section 5). Finally, a limit equi-

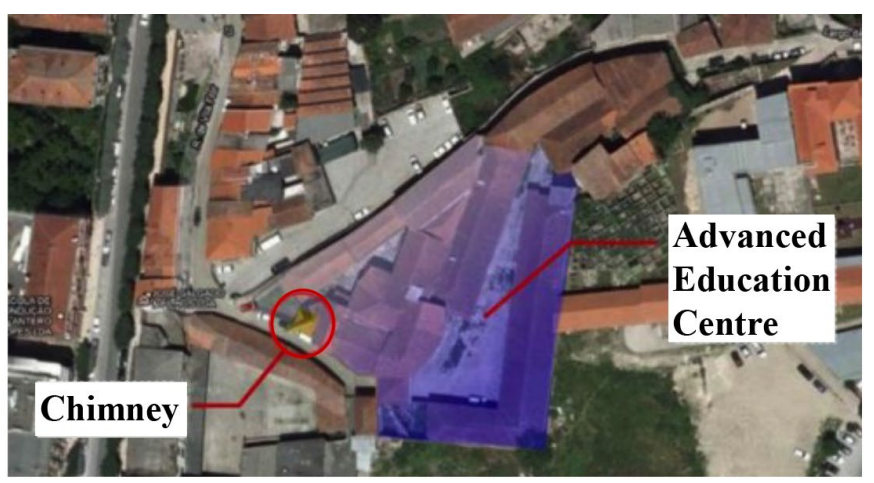

(a)

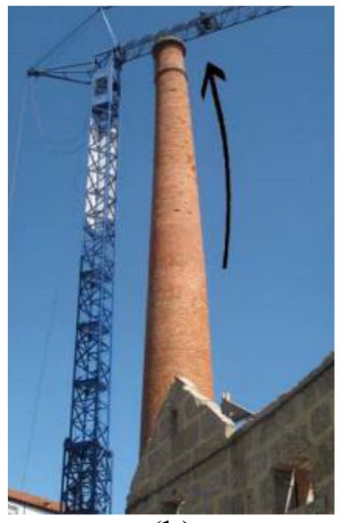

(b)

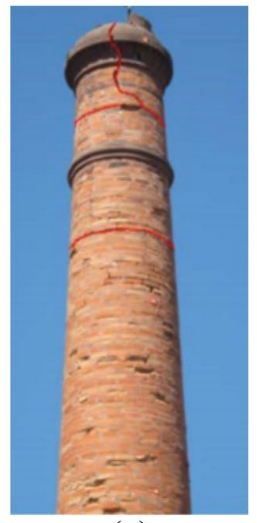

(c)

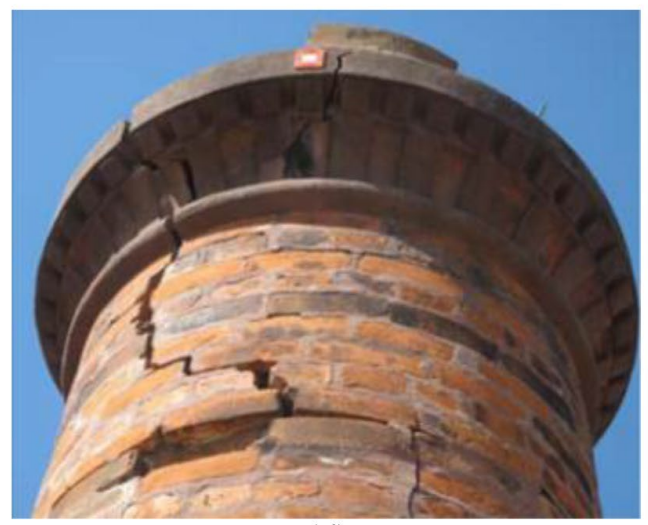

(d)

Figure 1. Location of the chimney (a) and view of the structure before the accident: (b) permanent deformation; (c-d) cracks triggering the disconnection of the top part. 

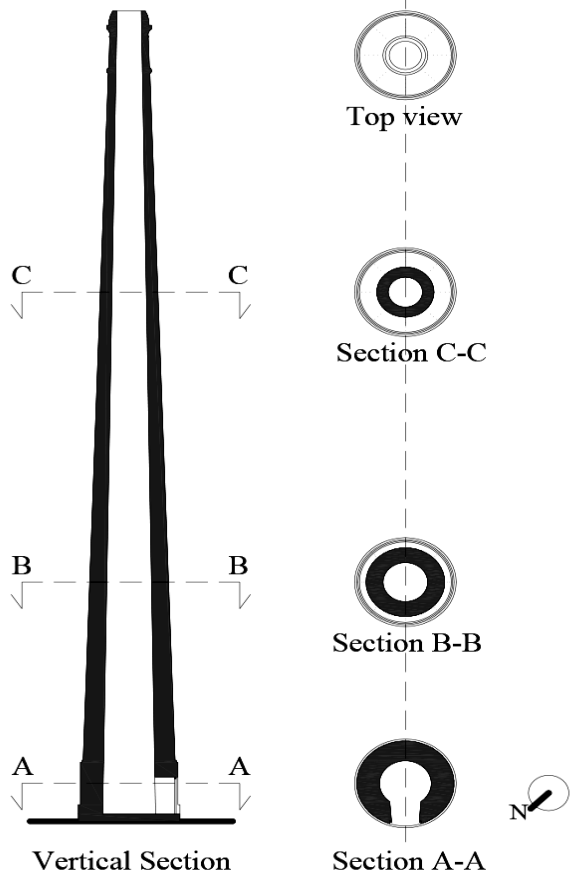

(a)

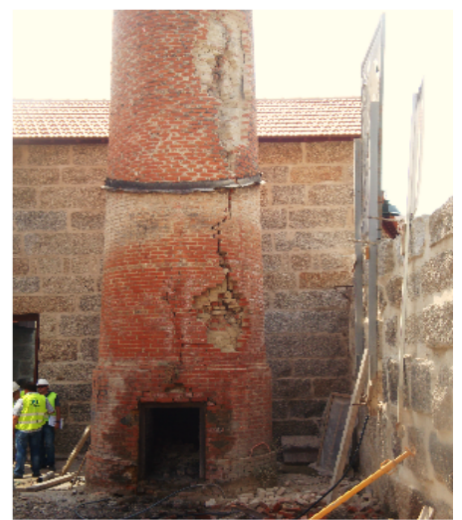

(c)
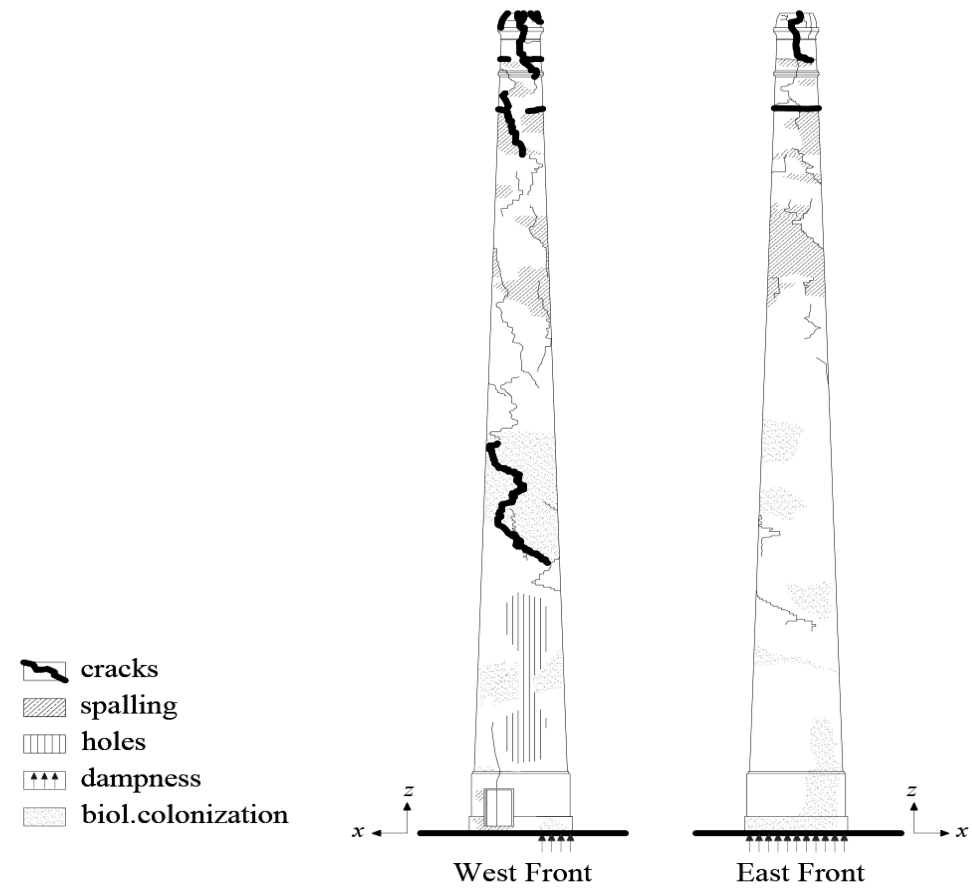

(b)

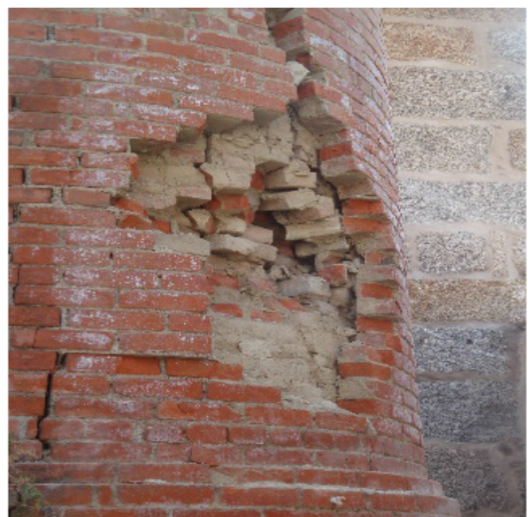

(d)

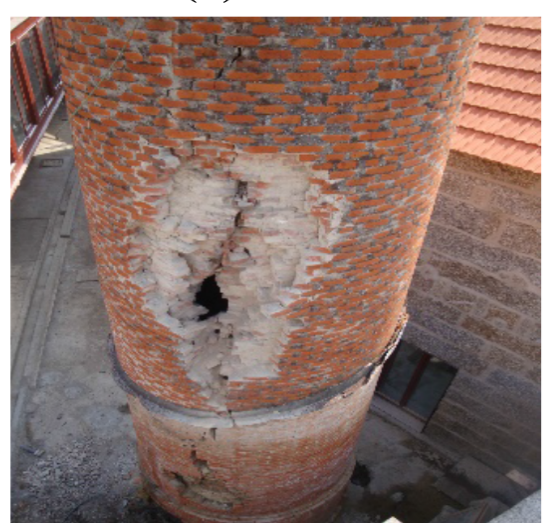

(e)

Figure 2. Masonry chimney: (a) geometrical features; (b) damage survey; (c), (d) and (e) photographic survey of the openings caused by the lightning.

librium analysis is carried out to evaluate the seismic capacity of the structure and assess its vulnerability level against horizontal actions (Section 6).

It is concluded that the dynamic properties of a structure are directly related to its seismic performance, therefore supervised SHM techniques are strongly encouraged in order to mitigate the risk of damage from earthquakes. In this regard, the spectral-based damage identification method shows to be a valuable non-destructive tool that can be successfully implemented in the engineering practice and integrated within a strategy for the structural assessment and preservation of built cultural heritage.

\section{Description of the Case-Study Structure}

The case-study structure is a masonry chimney belonging to a former industrial complex located in the city centre of Guimarães, historical town in the North of Portugal (Figure 1a). The structure was already object of monitoring between November 2010 and June 2011 when the University of Minho was in charge of assessing the structural condition during the building works of the neighbouring Advanced Education Centre. On that occasion, a campaign of topographical measurements and visual inspections detected a slight rigid rotation of the upper part of the chimney and several structural cracks. In addition, the survey pointed out a permanent plastic deformation affecting the upper two thirds of the flue and a disconnection of the top part from the rest of the body, owing to the presence of serious cracks at that level (Figure 1b-d). In July 2012 a lightning accident worsened the structural condition of the chimney. First, temporary remedial actions were undertaken with urgency to ensure the 
structural stability. Afterwards, an in-depth intervention was executed to reinstate the sound condition. During this lapse of time, the dynamic response of the structure was continuously monitored to follow the temporal evolution of the modal parameters and to control the effectiveness of the repair works [Ramos et al. 2013, Masciotta et al. 2014]. Dealing with two structural conditions, namely damaged state (before the intervention) and undamaged state (after the intervention), the acquired data were used as a benchmark for the supervised damage identification that will be described in the next sections.

\subsection{Geometrical Survey}

The chimney is built of brick masonry units with mortar joints arranged along regular horizontal courses and is characterized by a cone frustum shape with a pipe cross-section that tapers upwards, decreasing both in diameter (from $2.93 \mathrm{~m}$ to $0.94 \mathrm{~m}$ ) and thickness (from $0.70 \mathrm{~m}$ to $0.20 \mathrm{~m}$ ), see Figure 2a. Circa $27 \mathrm{~m}$ high, the chimney features an average height-diameter aspect ratio of about 14:1, being therefore defined as a slender structure. The chimney rests on a quadrangular foundation block and presents a rectangular opening ("door") of about $0.90 \mathrm{~m} \times 1.20 \mathrm{~m}$, used to trigger the 'chimney effect' for the dispersion of the smokes produced by the former industrial complex.

\subsection{Damage Survey and Structural Intervention}

The electrical discharge that struck the chimney, owing to the poor condition of the lightning rod located in the South-East side of the structure, blew up part of the wall opposite the rod, causing two significant new openings: one at $3 \mathrm{~m}$ height from the ground level (close to the chimney door) and another at $6 \mathrm{~m}$ height (Figure $2 \mathrm{~b}-\mathrm{e}$ ). The masonry bricks were completely hurled and fell on surrounding roofs about $15 \mathrm{~m}$ far. In spite of that, the chimney underwent no considerable change in terms of structural mass: the mass percentage difference between damaged and undamaged configurations resulted to be barely $4 \%$. Figure $2 \mathrm{~b}$ shows the damage survey after the lightning strike. The permanent deformation of the chimney did not vary with the accident but, besides the two openings, the width of the existing vertical cracks increased $3 \mathrm{~mm}$ (the initial crack width was $10 \mathrm{~mm}$ ). Moreover, due to lack of maintenance, the damage survey of November 2012 reported spotted spalling, widespread biological colonization and moist areas in the bottom part of the structure.

With the purpose of restoring the healthy condition, in-depth repair works were carried out between December 2012 and February 2013. The remedial measures in- cluded: structural consolidation through reconstruction of the damaged parts, cracks closing, grout injections, cleaning and waterproof protection. A few snapshots of the chimney during and after the rehabilitation works are shown in Figure 3.

\section{Dynamic Characterization of the System}

The major aim of this section is to analyse the modal behaviour of the chimney before and after the structural intervention and to compare the response of both scenarios in order to locate the damage, to qualitatively assess its extent and to evaluate the effi-
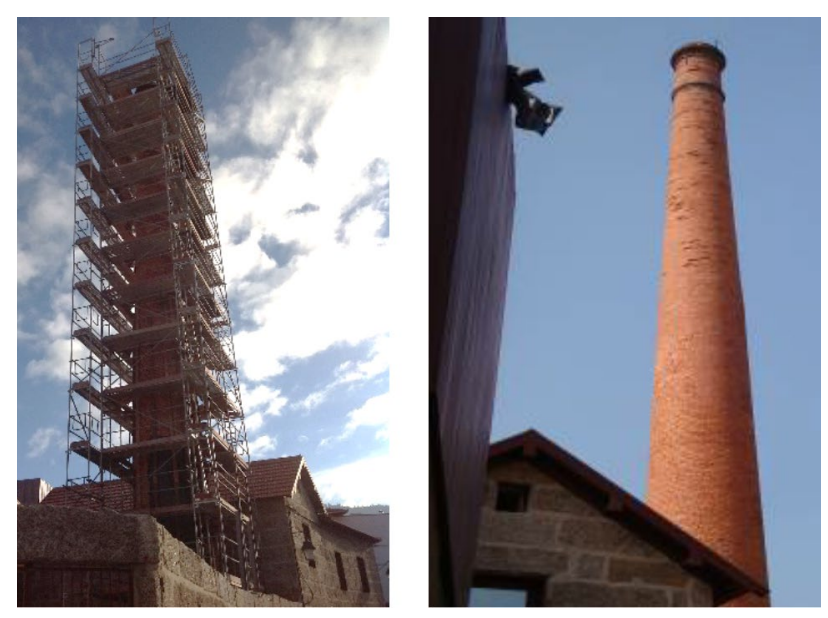

Figure 3. Structural intervention in the chimney: (a) view with the scaffolding for the works execution; (b) final configuration.

ciency of the consolidation works.

To characterize the dynamics of the system, an output-only modal analysis was carried out using environmental excitations from wind, traffic and human walking as operational conditions. A numerical modal analysis was performed beforehand to select and optimize sensors number and layout as well as to choose sampling frequency and time window for the acquisition process. The first ambient vibration test was conducted in November 2012, while the second one in February 2013. Each campaign took one full day of measurements. The dynamic acquisition system consisted of 12 uniaxial piezoelectric accelerometers (Figure 4a), with a bandwidth range from 0.15 to $1000 \mathrm{~Hz}$, a dynamic range of $\pm 0.5 \mathrm{~g}$, a sensitivity of $10 \mathrm{~V} / \mathrm{g}, 8 \mu \mathrm{g}$ of resolution and $210 \mathrm{~g}$ of weight, connected by coaxial cables to a front-end data acquisition unit with a 24 bit ADC provided with anti-aliasing filters. The system was connected to the laptop by an Ethernet cable (Figure 4b).

In order to study the modal response of the chimney in both horizontal and vertical directions, twenty DOFs deployed at ten different locations were measured and the scaffolding for the rehabilitation works was used 


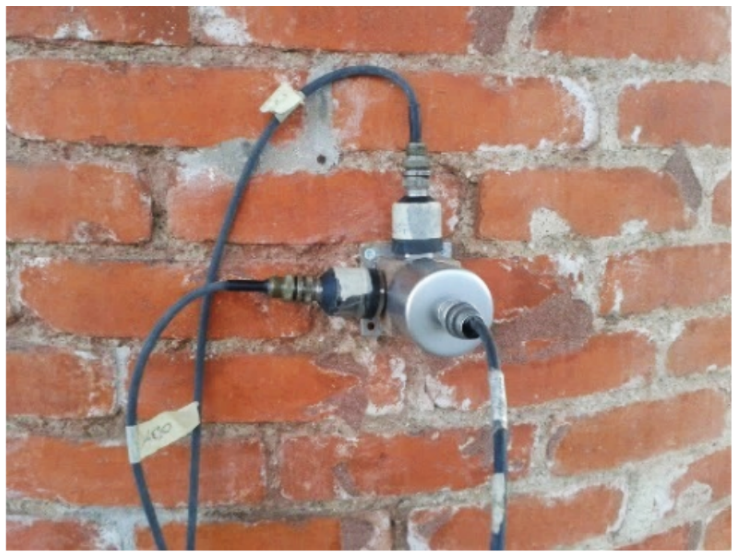

(a)

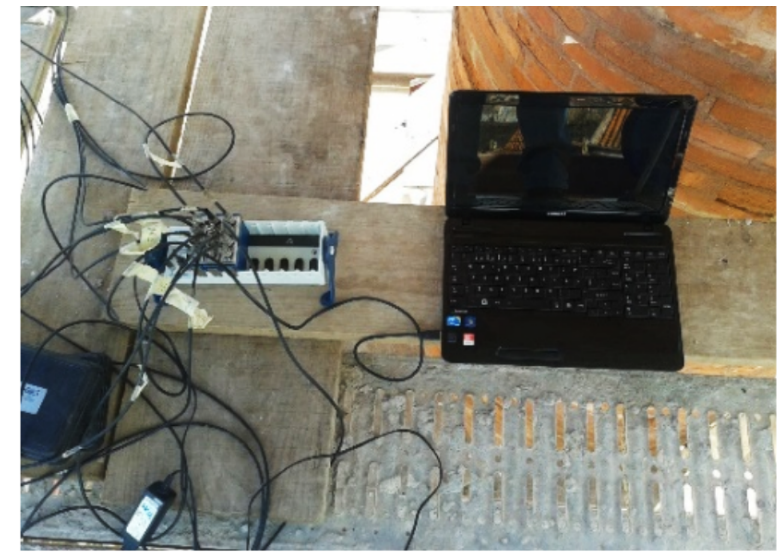

(b)
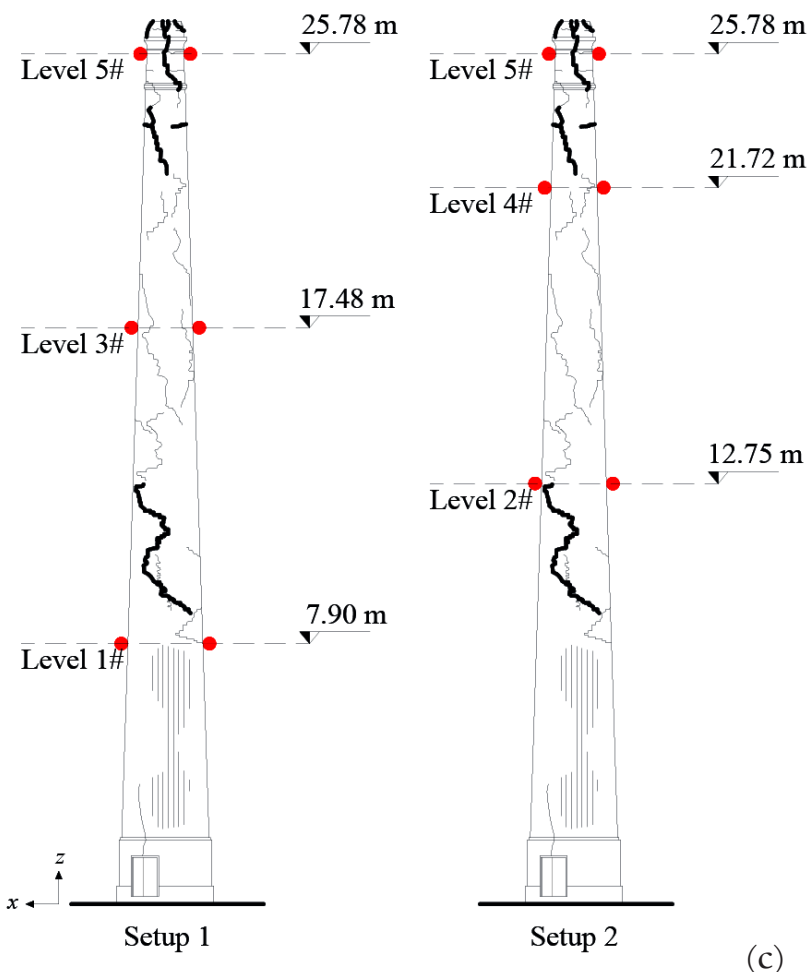

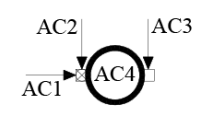

Level 5\#

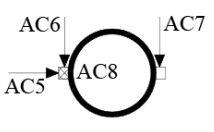

Level 3\#

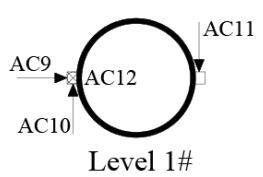

Setup 1

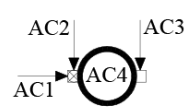

Level 5\#

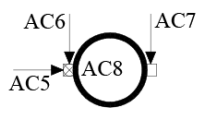

Level 4\#

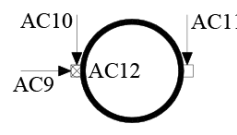

Level 2\#

Setup 2

(c)

Figure 4. Operational modal analysis: (a) deployment of piezoelectric accelerometers; (b) data acquisition system; (c) test setups - the measuring points are marked in red; and (d) monitored DOFs.

to access them. Not to interfere with the vibration tests, the scaffolding was appropriately detached from the structure. The response was acquired through two setups. Each setup consisted of three horizontal levels and each level consisted of four accelerometers: three of them were set on the northern wall along the orthogonal directions $\mathrm{x}, \mathrm{y}$ and $\mathrm{z}$, and the fourth one was placed on the southern wall along the y direction to catch possible torsional components in the modal response. The measuring points are indicated in Figure $4 \mathrm{c}-\mathrm{d}$. The four transducers located at the top of the structure were kept as reference sensors. Table 1 summarizes the test setups along with the relevant reference and moving sensors. According to the results of the preliminary numerical modal analysis, a sam- pling frequency of $200 \mathrm{~Hz}$ and a time window of 10 minutes were finally adopted for the recording. The general rule for ambient vibration tests recommends a measurement length of at least 1000 times greater than the fundamental period of the structure [Cantieni 2005], however, for the present case, 10 minutes resulted sufficient enough to catch all meaningful vibration characteristics of the system.

3.1 Modal Features Estimation Before and After the Structural Intervention

The dynamic features of the chimney before and after the rehabilitation works were estimated by two modal identification techniques: the Enhanced Frequency Domain Decomposition (EFFD) method 
MASCIOTTA ET AL.

\begin{tabular}{|c|c|c|c|c|c|c|c|}
\hline \multirow[t]{2}{*}{ Setup } & \multicolumn{2}{|c|}{ Ref. sensors } & \multicolumn{2}{|c|}{ Mov. Sensors 1} & \multicolumn{2}{|c|}{ Mov. Sensors 2} & \multirow[t]{2}{*}{ Direction } \\
\hline & Level & Nomenclature & Level & Nomenclature & Level & Nomenclature & \\
\hline \multirow{4}{*}{1} & \multirow{4}{*}{5} & $\mathrm{AC} 01$ & \multirow{4}{*}{1} & AC09 & \multirow{4}{*}{3} & $\mathrm{AC} 05$ & $x(\mathrm{~N})$ \\
\hline & & $\mathrm{AC} 02$ & & $\mathrm{AC} 10$ & & AC06 & $y(\mathrm{~N})$ \\
\hline & & $\mathrm{AC} 03$ & & $\mathrm{AC} 11$ & & $\mathrm{AC} 07$ & $y(S)$ \\
\hline & & $\mathrm{AC} 04$ & & $\mathrm{AC} 12$ & & $\mathrm{AC} 08$ & $z(\mathrm{~N})$ \\
\hline \multirow{4}{*}{2} & \multirow{4}{*}{5} & $\mathrm{AC} 01$ & \multirow{4}{*}{2} & AC09 & \multirow{4}{*}{4} & $\mathrm{AC} 05$ & $x(\mathrm{~N})$ \\
\hline & & AC02 & & AC10 & & AC06 & $y(\mathrm{~N})$ \\
\hline & & $\mathrm{AC} 03$ & & $\mathrm{AC} 11$ & & AC07 & $y(S)$ \\
\hline & & $\mathrm{AC} 04$ & & $\mathrm{AC} 12$ & & AC08 & $z(\mathrm{~N})$ \\
\hline
\end{tabular}

Table 1. Detailed list of reference and moving sensors used for the dynamic identification.

\begin{tabular}{|c|c|c|c|c|c|c|c|c|c|c|}
\hline \multirow{2}{*}{ Mode } & \multicolumn{2}{|c|}{ Before } & \multicolumn{2}{|c|}{ After } & \multicolumn{4}{|c|}{ Before } & \multicolumn{2}{|c|}{ fter } \\
\hline & $\omega(\mathbf{H z})$ & $\mathrm{CV}(\%)$ & $\omega(\mathbf{H z})$ & $\mathrm{CV}(\%)$ & $\Delta_{\omega}(\%)$ & $\zeta(\%)$ & $\mathrm{CV}(\%)$ & $\zeta(\%)$ & $\mathrm{CV}_{\varepsilon}(\%)$ & $\Delta_{\zeta}(\%)$ \\
\hline $1^{\text {st }}$ & 1.02 & 0.26 & 1.02 & 0.18 & +0.30 & 0.48 & 65.53 & 2.53 & 2.43 & +429.6 \\
\hline $2^{\text {nd }}$ & 1.15 & 0.08 & 1.10 & 0.05 & -4.09 & 0.95 & 20.91 & 3.30 & 6.25 & +248.3 \\
\hline $3^{\text {rd }}$ & 3.20 & 0.75 & 3.39 & 0.26 & +5.90 & 0.91 & 29.18 & 1.36 & 8.60 & +49.43 \\
\hline $4^{\text {th }}$ & 3.65 & 0.18 & 3.73 & 0.33 & +2.11 & 0.90 & 15.07 & 1.96 & 6.58 & +117.6 \\
\hline $5^{\text {th }}$ & 6.39 & 0.50 & - & - & - & 0.75 & 45.42 & - & - & - \\
\hline $6^{\text {th }}$ & 7.32 & 0.24 & 7.79 & 0.21 & +6.51 & 0.84 & 39.77 & 1.09 & 10.77 & +30.26 \\
\hline $7^{\text {th }}$ & 8.81 & 0.05 & 10.29 & 0.03 & +16.85 & 0.58 & 9.79 & 0.91 & 24.17 & +56.44 \\
\hline $8^{\text {th }}$ & 11.40 & 0.07 & 12.51 & 0.32 & +9.74 & 1.24 & 31.92 & 1.84 & 1.94 & +47.91 \\
\hline $9^{\text {th }}$ & 12.31 & 0.22 & 13.37 & 0.38 & +8.61 & 1.46 & 16.22 & 1.58 & 24.21 & +7.87 \\
\hline $10^{\text {th }}$ & 13.93 & 0.19 & 13.53 & 0.28 & -2.87 & 2.56 & 33.33 & 2.29 & 39.97 & -10.62 \\
\hline Average & - & 0.40 & - & 0.23 & $+7.95^{\star}$ & 1.21 & 27.31 & 1.87 & 13.88 & $+123.43^{\star}$ \\
\hline
\end{tabular}

*Average value calculated only with positive differences and for comparable modes.

Table 2. Comparison of estimated frequency values and damping coefficients before and after the rehabilitation works.

\begin{tabular}{|c|c|c|c|c|c|c|c|c|c|c|c|}
\hline & $\zeta$ & $1^{\mathrm{st}}$ & $2^{\text {nd }}$ & $3^{\text {nd }}$ & $4^{\text {th }}$ & $6^{\text {th }}$ & $7^{\text {th }}$ & $8^{\text {th }}$ & $9^{\text {th }}$ & $10^{\text {th }}$ & $\operatorname{avg}_{\text {tot }}$ \\
\hline \multirow{3}{*}{$\begin{array}{l}\stackrel{0}{0} \\
\stackrel{0}{0} \\
\infty\end{array}$} & avg & 0.48 & 0.95 & 0.91 & 0.9 & 0.84 & 0.58 & 1.24 & 1.46 & 2.56 & 1.21 \\
\hline & $\sigma$ & 0.32 & 0.20 & 0.27 & 0.14 & 0.33 & 0.06 & 0.40 & 0.24 & 0.85 & 0.31 \\
\hline & $\mathrm{CV}$ & 0.66 & 0.21 & 0.29 & 0.15 & 0.40 & 0.10 & 0.32 & 0.16 & 0.33 & 0.27 \\
\hline \multirow{3}{*}{ 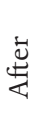 } & avg & 2.53 & 3.3 & 1.36 & 1.96 & 1.09 & 0.91 & 1.84 & 1.58 & 2.29 & 1.87 \\
\hline & $\sigma$ & 0.06 & 0.21 & 0.12 & 0.13 & 0.12 & 0.22 & 0.04 & 0.38 & 0.92 & 0.24 \\
\hline & CV & 0.02 & 0.06 & 0.09 & 0.07 & 0.11 & 0.24 & 0.02 & 0.24 & 0.40 & 0.14 \\
\hline
\end{tabular}

Table 3. Statistics of damping coefficients before and after strengthening for comparable vibration modes.

[Brincker et al. 2001] and the Stochastic Subspace Identification (SSI) method - Principal Component [Peeters et al. 1999], both implemented in ARTeMIS [SVS 2011]. The outcomes of the modal estimation are presented in Figure 5 and Table 2. It is noted that the reduction of damage-induced local effects after the works resulted in the vanishing of several vibration modes, which were most likely modes originated from the presence of damage. It is also stressed that the lower modes only suffer a slight frequency shift between damage and undamaged scenarios, whereas the higher modes undergo significant changes. An average frequency increase of about $8 \%$ is registered, meaning that the structural intervention did yield stiffness improvements. On the other 

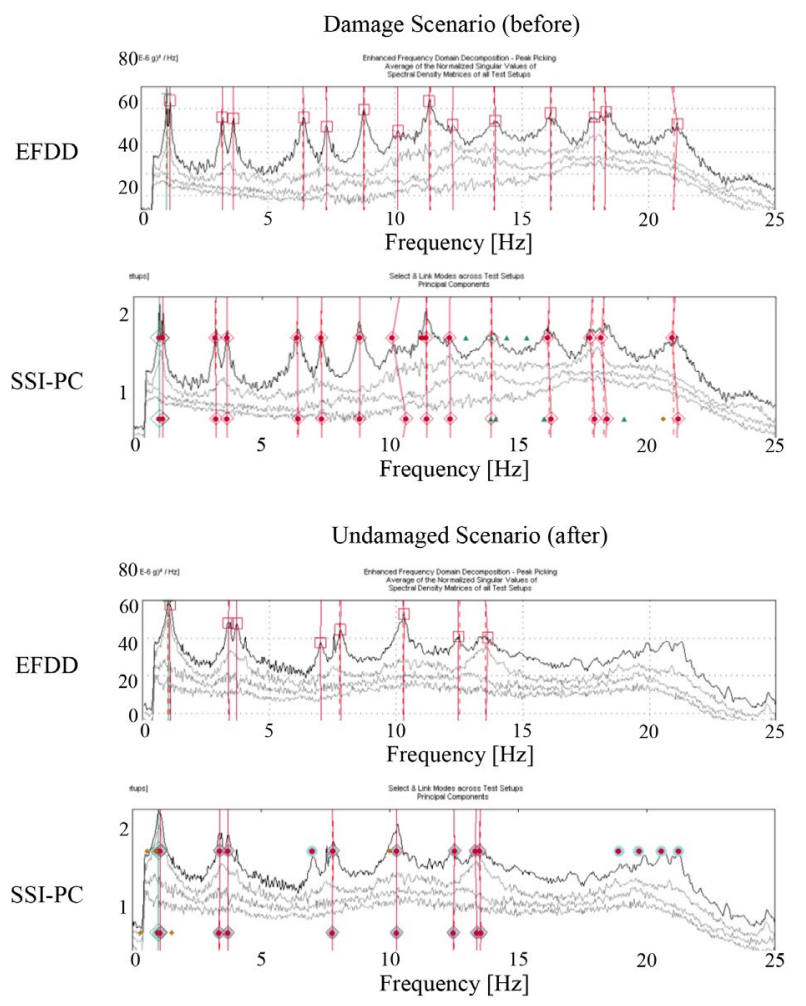

Figure 5. Modal features estimation before and after works: Enhanced Frequency Domain Decomposition vs Stochastic Subspace Identification.

hand, an unexpected increase of damping ratio is found (on average $120 \%$ ). As a rule, the vibration modes of a damaged structure feature higher damping values than their no-damaged counterparts. However, the accurate quantification of damping coefficients is not easy as this modal parameter is affected by strong uncertainties and presents much higher statistical variation from random error sources than modal frequencies. Indeed, looking in more detail at the statistics of damping values before and after strengthening (Table 3), it is observed that the dispersion of damping results is higher for the first dynamic identification, where the average Coefficient of Variation (CV) and standard deviation $\sigma$ equal $27 \%$ and 0.31 , respectively, against $14 \%$ and 0.24 of the second modal test. This is imputable to the lower signal-tonoise ratio recorded during the first dynamic test. Given the uncertainty in the estimation of damping coefficients, these parameters are not used as damage-sensitive features.

The mode shapes identified before and after the works are displayed in Figure 6 along with the corresponding MAC values. Despite a good fit in terms of configuration, the correlation between comparable modes of damage and undamaged states is rather moderate (low MAC values) save for the lower modes. The detailed inspection of the modal displacements enables to understand that this is due to the fact that the structur- al response is marked by local effects in the areas where the two openings and the most severe cracks are located, while a monolithic behaviour characterizes the system after the intervention.

The results discussed hitherto allow to infer that the presence of damage affected the dynamic behaviour of the chimney mostly with regard to the higher modes whose frequencies increased considerably after repairing the damaged areas. To further assess the effectiveness of the rehabilitation works and verify if cracks have stabilized, the results from the continuous dynamic monitoring are analysed and presented hereafter.

\subsection{Short-term Structural Health Monitoring}

To follow the evolution of its modal features during the works, the chimney was monitored using the four reference accelerometers placed at the top (Level 5). The acquisition software was properly set to record circa 10 minutes of ambient vibrations every hour with a sampling frequency of $100 \mathrm{~Hz}$. The monitoring task was carried out in three campaigns within the period

\begin{tabular}{lccc}
\hline Data series & From & To & $\begin{array}{c}\text { Number of } \\
\text { events }\end{array}$ \\
\hline I & 5-Dec-12 & 14-Dec-12 & 160 \\
II & 18-Dec-12 & 22-Dec-12 & 73 \\
III & 4-Jan-13 & 22-Jan-13 & 313 \\
\hline
\end{tabular}

Table 4. Data series of the monitoring campaign.

December 2012 - January 2013 and a total number of 546 events was collected. Particular attention was paid during the reconstruction of the masonry panels in the areas where the lightning caused the openings. Data series, duration of each campaign and number of events per campaign are detailed in Table 4 .

Dealing with several events, the modal features extraction is performed through an automatic processing algorithm based on the Stochastic Subspace Identification (SSI) method [Peeters et al. 1999] and implemented as a subroutine in MATLAB [MATLAB 2010]. To avoid unrealistic results, a few events are manually analysed before the automatic data processing so as to set threshold values for frequencies, damping ratios (usually between $1 \%$ and $5 \%$ ) and MAC values (greater than 0.95). Then, the maximum model order is fixed. It is known that the selection of small model orders can make difficult the identification of weakly excited modes, but the choice of inapt large orders can result in the appearance of many spurious modes associated with the noise content of the measurements. In the present application, after testing different values of 

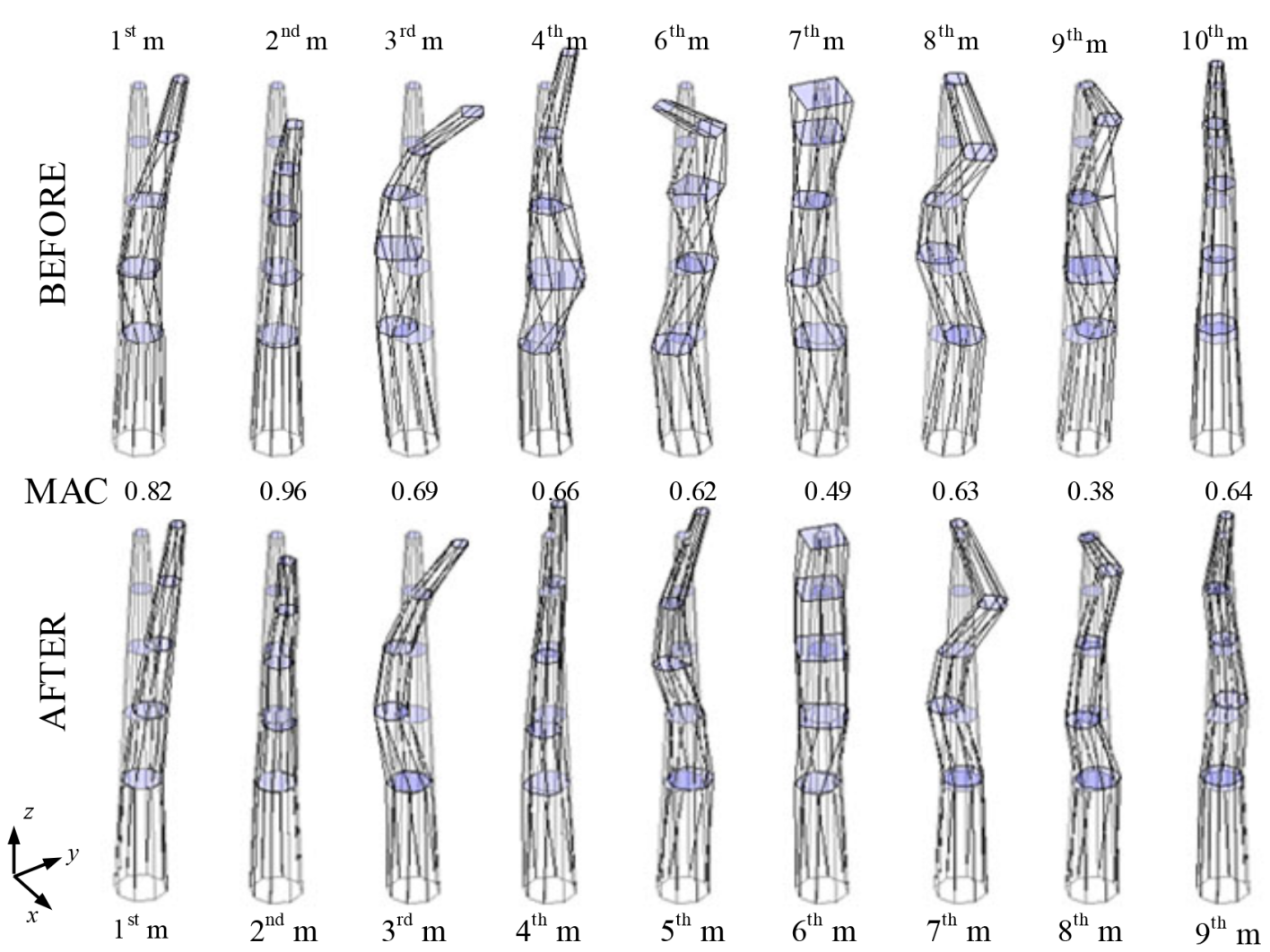

Figure 6. Experimental mode shapes and MAC values before and after the intervention.

model order in the range $20-100$ with increments of 10 , a maximum model order of 30 is selected. Figure 7 presents the results of the automatic dynamic identification for the first six vibration modes of the chimney. The plot confirms that the major changes between damage and undamaged scenarios concerned the high-frequency modes, whereas the low-frequency modes did not suffer considerable variations. This outcome was largely expected: unlike low-frequency

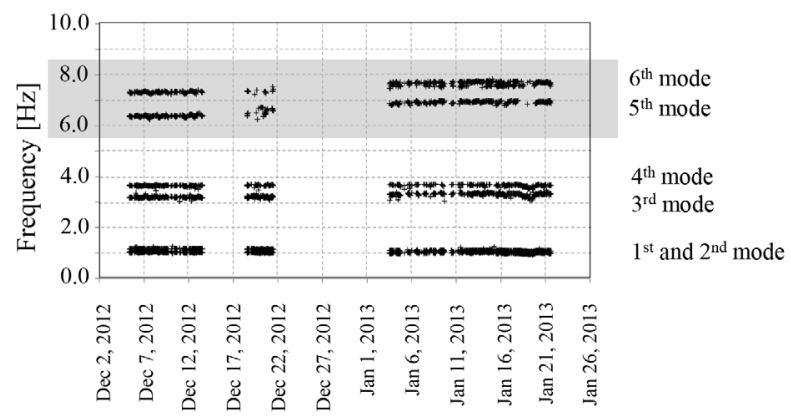

Figure 7. Evolution of the first six natural frequencies over the monitoring period.

modes, which are associated with the global dynamic behaviour of the structure, high-frequency modes are local modes, thereby being more sensitive to changes in frequency as well as in mode shape configuration when local phenomena, such as structural damage, occur. In addition, higher modes have more inflexion points (nodal points), and the effects of cracks are sig- nificant on the modal curvatures (or mode shapes).

It is worth noting that frequency shifts in masonry structures may be associated with factors other than damage, e.g. temperature fluctuations. For the present case study, although ambient parameters were not directly measured, it was possible to assess trends of temperature and relative humidity from the data acquired through the static monitoring system installed in a church close by. A close-up of the variation of both aforementioned parameters over the investigated period is reported in Figure 8. As it can be observed, no significant fluctuation occur between December 2012 and January 2013 as the air temperature keeps around $11^{\circ} \mathrm{C}$ throughout the period, featuring very marginal oscillations, and the relative humidity fluctuates around an average value of $82 \%$ with only two minor drops. It is also important to stress that temperature changes have uniform influence on eigenfrequencies and eigenmodes, whereas structural damage has a selective influence on the dynamic parameters [Peeters and De Roeck 2001, Reynders and De Roeck 2009]. For all these reasons, any possible correlation between environmental factors and frequency changes in the chimney is excluded. As no further deviation in the frequency values is detected after the repair, it is concluded that cracks have stabilized and the structural intervention has efficiently reinstated the sound state of the chimney. 


\section{Spectral-based Damage Identification}

\subsection{Theoretical Framework}

In stochastic environment, the dynamic characterization of structural systems can be performed by applying spectral analysis methods based on the use of frequency-varying spectral features called power spectral density functions. Once the nodal response processes $X i(t)(i=1, . ., \mathrm{m})$ of a given structural system are known, the relevant power spectral densities can be estimated through the Fourier Transforms of the corresponding time-domain correlation functions, and then collected into the Power Spectral Density (PSD) matrix as follows:

$\mathbf{S}_{X}(\omega, T)=\left[\begin{array}{cccc}S_{X_{1} X_{1}}(\omega, T) & S_{X_{1} X_{2}}(\omega, T) & \cdots & S_{X_{1} X_{m}}(\omega, T) \\ S_{X_{2} X_{1}}(\omega, T) & S_{X_{2} X_{2}}(\omega, T) & \cdots & S_{X_{2} X_{m}}(\omega, T) \\ \cdots & \cdots & \ddots & \cdots \\ S_{X_{m} X_{1}}(\omega, T) & \cdots & \cdots & S_{X_{m} X_{m}}(\omega, T)\end{array}\right]$

where diagonal and out-of-diagonal elements represent the direct and cross power spectral densities of the measured nodal response processes $X i(\omega, T)$, respectively. Since direct spectral densities are real functions, while cross spectral densities are complex conjugate functions, it follows that the matrix defined in Equation (1) is a Hermitian matrix composed of a symmetric real part and an anti-symmetric imaginary part, thus admitting real positive-defined eigenvalues $\lambda i(\omega)$ and complex eigenvectors $\Psi_{i}(\omega)$. Hence, the properties of the system's PSD matrix $\boldsymbol{S}_{X}$ can be analysed through its eigenvalue decomposition:

$$
\mathbf{S}_{X}(\omega)=\Psi_{X}(\omega) \Lambda_{X}(\omega) \Psi_{X}^{H}(\omega)
$$

in which

$$
\begin{aligned}
\Lambda_{X}(\omega) & =\left[\begin{array}{cccc}
\lambda_{1}(\omega) & 0 & 0 & 0 \\
0 & \lambda_{2}(\omega) & 0 & 0 \\
0 & 0 & \ddots & 0 \\
0 & 0 & 0 & \lambda_{n}(\omega)
\end{array}\right]=\left[\begin{array}{cccc}
1 / \omega_{1}^{2} & 0 & 0 & 0 \\
0 & 1 / \omega_{2}^{2} & 0 & 0 \\
0 & 0 & \ddots & 0 \\
0 & 0 & 0 & 1 / \omega_{n}^{2}
\end{array}\right] \\
\Psi_{X}(\omega) & =\left[\begin{array}{cccc}
\psi_{11}(\omega) & \psi_{12}(\omega) & \cdots & \psi_{1 n}(\omega) \\
\psi_{21}(\omega) & \psi_{22}(\omega) & \cdots & \psi_{2 n}(\omega) \\
\vdots & \vdots & \ddots & \vdots \\
\psi_{n 1}(\omega) & \psi_{21}(\omega) & \cdots & \psi_{n n}(\omega)
\end{array}\right]
\end{aligned}
$$

and $\Psi_{X}^{H}(\omega)$ is the complex conjugate transpose of $\Psi_{X}(\omega)$. The diagonalization of the eigenvalue matrix $\Lambda_{X}(\omega)$ yields the eigenfrequencies of the system as local maxima, being each element $\lambda_{j}(\omega)$ of $\Lambda_{X}(\omega)$ a frequen- cy-dependent parameter proportional to the energy of a certain vibration mode. On the contrary, the eigenvector matrix $\Psi_{X}(\omega)$ consists of mutually orthogonal coordinate-dependent parameters $\psi_{j}(\omega)$, each providing the estimate of a mode shape of the system. Fulcrum of the spectral approach is the accurate estimation of these eigenparameters which allow not only for the dynamic characterization of the structure under analysis, but also for the detection and localisation of possible faults and damage areas, as it will be proved in next section.

\subsection{Derivation of the Spectral Formulation}

A multivariate stochastic vector process $\mathbf{X}(t)$ with power spectrum matrix $\mathbf{S}_{X}(\omega)$ can be expressed as a summation of $m$ independent fully coherent stochastic processes [Di Paola 1998] that are proportional to the eigenvectors $\Psi_{k}\left(\omega_{j}\right)$ and eigenvalues $\lambda_{k}\left(\omega_{j}\right)$ estimated from the PSD matrix of the process itself:

$$
\mathbf{X}(t)=\sum_{k=1}^{m} \mathbf{Y}_{k}(t)=\sum_{k=1}^{m} 2 \sqrt{\Delta \omega} \operatorname{Re}\left(\sum_{j=1}^{n} \Psi_{k}\left(\omega_{j}\right) \sqrt{\lambda_{k}\left(\omega_{j}\right)} \cdot P_{j}^{(k)} e^{i \omega_{j} t}\right)
$$

where $\operatorname{Re}[\bullet]$ returns the real part of the complex value expression and $P_{j}^{(k)}$ is a random complex number defined as follows:

$$
P_{j}^{(k)}=R_{j}^{(k)}-i I_{j}^{(k)}
$$

$R_{j}^{(k)}$ and $I_{j}^{(k)}$ being zero-mean normal random numbers obeying the following orthogonality relationships:

$$
E\left[R_{j}^{(r)} R_{j}^{(s)}\right]=\frac{1}{2} \delta_{j k} \delta_{r s} E\left[I_{j}^{(r)} I_{j}^{(s)}\right]=\frac{1}{2} \delta_{j k} \delta_{r s} E\left[R_{j}^{(r)} I_{j}^{(s)}\right]=0
$$

and $\delta$ being the Kronecker delta $\left(\delta_{j k}=1\right.$ if $\mathrm{j}=k, \delta_{j k}=$ 0 if $\mathrm{j} \neq k$ ).

It follows that the difference between two multivariate stochastic vector processes, e.g. reference $\mathbf{X}(t)$ and damage $\mathbf{X}^{d}(t)$, can be expressed as shown below [Masciotta et al. 2016]:

$$
\begin{gathered}
\Delta \mathbf{X}(t)=\mathbf{X}^{d}(t)-\mathbf{X}(t)=\sum_{k=1}^{m}\left(\mathbf{Y}_{k}^{d}(t)-\mathbf{Y}_{k}(t)\right) \\
\Delta \mathbf{X}(t)=2 \sqrt{\Delta \omega} \operatorname{Re}\left(\sum_{k=1}^{m} \sum_{j=1}^{n} \Delta \Psi_{k}\left(\omega_{j}\right) \cdot P_{j}^{(k)} e^{i \omega_{j} t}\right)
\end{gathered}
$$

where:

$$
\Delta \Psi_{k}\left(\omega_{j}\right)=\Psi_{k}^{d}\left(\omega_{j}\right) \sqrt{\lambda_{k}^{d}\left(\omega_{j}\right)}-\Psi_{k}\left(\omega_{j}\right) \sqrt{\lambda_{k}\left(\omega_{j}\right)}
$$

The complex function $\Delta_{\Psi k}\left(\omega_{j}\right)$ acts as a natural damage indicator: if no damage occurs in the structure, $\Delta_{\Psi k}\left(\omega_{j}\right)$ will be equal to zero for any $k$ and $j$ and the expression $\Delta \mathbf{X}(t)=\mathbf{X}^{\mathrm{d}}(t)-\mathbf{X}(t)$ will result null; whereas if damage occurs in the structure, the indicator $\Delta_{\Psi k}\left(\omega_{j}\right)$ will be different than zero for a given $k$ 
and will result in a value related to the magnitude of damage.

As demonstrated above, system's changes due to evolutionary damage scenarios lead to changes in the response PSD matrix and its eigenparameters. Thus, spectral eigenvalues and eigenvectors can be used as damage-sensitive features for supervised structural health monitoring. In particular, eigenvalues shifts between different scenarios can allow to detect the presence of damage in the structure, whereas changes in the eigenvectors can provide spatial information about the damage position [Masciotta 2015]. Taking this into account, the authors have defined and successfully validated [Masciotta et al. 2017, Masciotta et al. 2016], the following spectral damage localization index:

$$
\Delta \Psi=\sum_{k=1}^{m}|| \sum_{j=1}^{n}\left[\Psi_{k}^{d}\left(\omega_{j}\right) \sqrt{\lambda_{k}^{d}\left(\omega_{j}\right)}\right]|-| \sum_{j=1}^{n}\left[\Psi_{k}^{u}\left(\omega_{j}\right) \sqrt{\lambda_{k}^{u}\left(\omega_{j}\right)}\right] \|
$$

where $n$ specifies the frequency range, $m$ indicates the eigenvector number and upper scripts $d$ and $u$ stand for damaged and undamaged conditions, respectively. The index $\Delta_{\Psi}$ in Equation (10) is given by the sum of the differences between the spectral modes of damaged and undamaged scenarios. Each spectral mode is obtained through the amplification of the eigenvectors extracted from the response PSD matrix by the square root of the corresponding eigenvalues. The number of spectral modes equals the number of non-zero eigenvalues. The so-defined spectral index $\Delta_{\Psi}$ will ultimately result in a vector of scalars, each one associated with the damage/ non-damage of a certain DOF. A comprehensive description of the spectrum-driven method can be found elsewhere [Masciotta et al. 2017, Masciotta et al. 2016]. In what concern the present work, the main goal is to apply the spectral formulation to a full-scale structure in order to demonstrate the potential of this tool for the structural assessment of built cultural heritage.

\section{Application of the Spectral Method to the Case-Study}

\subsection{Damage detection via Eigenvalues Analysis}

To comply with the spectral procedure, the output data collected via OMA are used to estimate direct and cross power spectral densities. In order to merge the data from different setups and build a unique power spectrum matrix, the acceleration time histories are first scaled with respect to the average difference (RMS) of the time series of one fixed reference sensor. Then, the PSD estimates are com- puted in MATLAB [MATLAB 2010] from the N-point DFTs of the relevant nodal response processes sampled at $200 \mathrm{~Hz}$, where $\mathrm{N}$ is the next power of two greater than the length of the signal. Given the limited number of data samples, a FFT length longer than the data length is used in the spectrum estimation so as to provide a higher resolution frequency of isolated spectral peaks above the noise floor. In detail, the power spectrum is split into 65536 bins which results in a frequency resolution (FR) of $0.003 \mathrm{~Hz} /$ bin. The default Hamming window with $50 \%$ overlap is applied to the datasets. A unique [15x15] PSD matrix is built by using the spectral output signals in $\mathrm{x}$ and $\mathrm{z}$ directions for the 5 measuring points on the northern side of the chimney and the spectral output signals in y direction for the 5 measuring points on the southern side. Therefore, all three orthogonal directions are involved in the diagonalization of the PSD matrix and the subsequent eigenfrequencies identification.

Figure 9a-b shows the eigenvalues plotting for both damage and undamaged scenarios, where the number of plotted eigenvalues equals the number of measured DOFs ( 5 per direction, 15 in total). The local maxima yielded by the eigenvalues coincide with the eigenfrequencies of the system. Ten and nine vibration modes are identified in the range $0-15 \mathrm{~Hz}$ for damaged and undamaged states, respectively. The relevant frequency values result to be consistent with the ones obtained from the more traditional SSI-PC method previously presented, reading the same percentage increase of $8 \%$, evidence of the stiffness improvement gained with the consolidation works. Figure $9 \mathrm{c}-\mathrm{d}$ and Table 5 present the detailed comparison between the eigenfrequencies estimated through the two different techniques. The curves show a very good fitting, being the maximum percentage error lower than $0.8 \%$ with the only exception of the second mode in the undamaged condition. The frequency shift concerning the higher modes is caught as well, and it proves to be a qualitative indicator of the presence of damage in the structure.

\subsection{Damage Localization \& Assessment}

As damage is a local phenomenon, complex eigenvectors must be considered to attain a higher level of damage identification. Unlike eigenvalues, eigenvectors are much more sensitive to damage-induced local effects since they are functions of the system's nodal coordinates. In virtue of that, the damage spectral analysis is performed by investigat- 


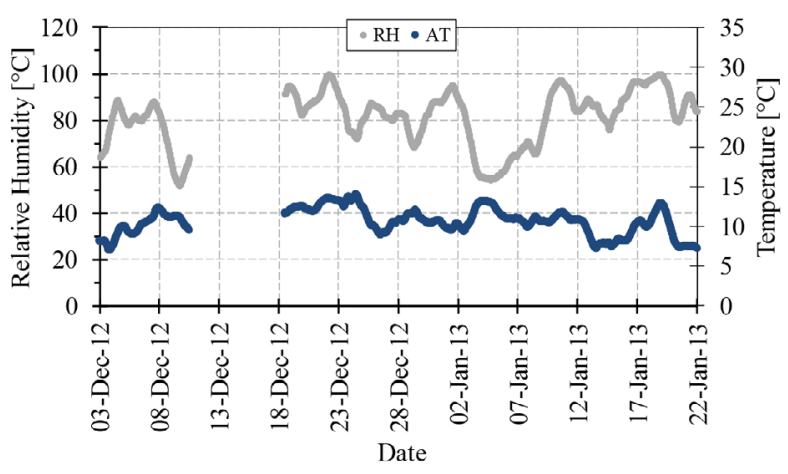

Figure 8. Temporal variation of air temperature and relative humidity over the monitoring period (data are measured through a combined temperature/humidity sensor installed in a nearby church).

ing $x-z$ and $y-z$ planes separately. The $x$-y plane has not been considered because of the low amplitude values of the acceleration responses in vertical direction $(z)$. The a priori knowledge of the damage position resulted from the in situ investigations is exploited as a reference parameter to weigh the reliability of the spectral-based damage identification.

In order to solve the eigenvalue problem described in Section 4, two different PSD matrices are built and

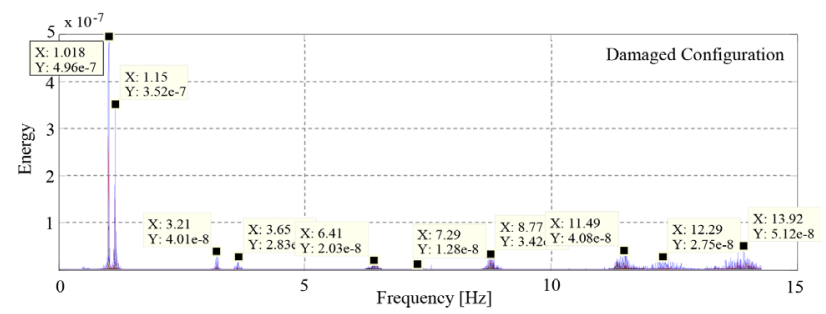

(a)

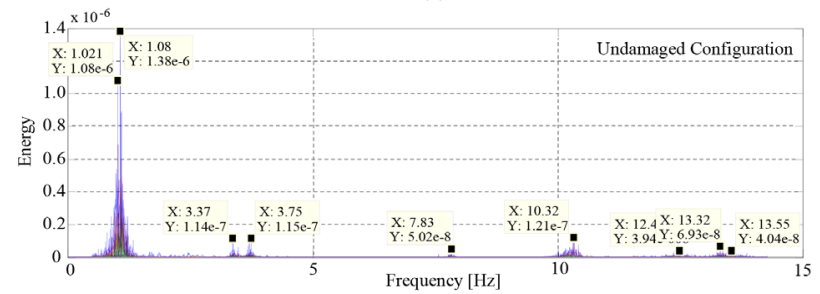

(b)

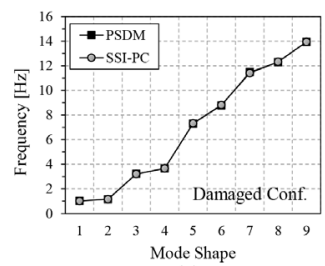

(c)

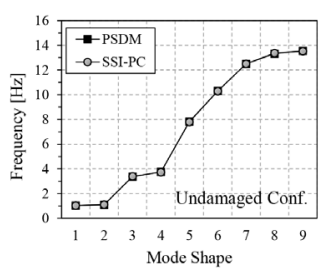

(d)
Figure 9. Eigenvalues plotting for (a) damaged state (before works) and (b) undamaged state (after works); and (c-d) eigenfrequencies comparison between PSD Method and SSI.

\begin{tabular}{|c|c|c|c|c|c|c|}
\hline \multirow{2}{*}{ Mode } & \multicolumn{3}{|c|}{ Before } & \multicolumn{3}{|c|}{ After } \\
\hline & $\omega_{\mathrm{PSD}}[\mathrm{Hz}]$ & $\omega_{\text {SSI }}[\mathrm{Hz}]$ & $\Delta_{\omega}[\mathrm{Hz}]$ & $\omega_{\mathrm{PSD}}[\mathrm{Hz}]$ & $\omega_{\text {SSI }}[\mathrm{Hz}]$ & $\Delta_{\omega}[\%]$ \\
\hline $1^{\text {st }}$ & 1.02 & 1.02 & +0.29 & 1.02 & 1.02 & +0.29 \\
\hline $2^{\text {nd }}$ & 1.15 & 1.15 & +0.17 & 1.08 & 1.10 & -1.82 \\
\hline $3^{\text {rd }}$ & 3.21 & 3.20 & +0.31 & 3.37 & 3.39 & -0.58 \\
\hline $4^{\text {th }}$ & 3.65 & 3.65 & +0.08 & 3.75 & 3.73 & +0.54 \\
\hline $5^{\text {th }}$ & 6.41 & 6.39 & +0.31 & - & - & - \\
\hline $6^{\text {th }}$ & 7.29 & 7.32 & -0.41 & 7.83 & 7.79 & +0.51 \\
\hline $7^{\text {th }}$ & 8.77 & 8.81 & +0.45 & 10.32 & 10.29 & +0.29 \\
\hline $8^{\text {th }}$ & 11.49 & 11.40 & +0.79 & 12.49 & 12.51 & -0.16 \\
\hline $9^{\text {th }}$ & 12.29 & 12.31 & -0.16 & 13.32 & 13.37 & -0.37 \\
\hline $.1510^{\text {th }}$ & 13.92 & 13.93 & -0.07 & 13.55 & 13.53 & +0.15 \\
\hline
\end{tabular}

Table 5. Spectral modes vs experimental modes: eigenfrequencies comparison.

decomposed: a [5x5] square matrix with spectral out-

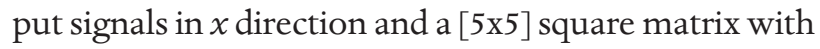
spectral output signals in $y$ direction. Once all eigenparameters are extracted from either matrix and for both structural conditions, the damage index in Equation (10) is computed allowing to compare the spectral modes of damaged and undamaged states for each investigated direction. Note that in OMA, especially in case where damage has to be quantitatively identified, it is mandatory to scale the experimental mode shapes with respect to the mass. Scaling factors do not affect the vibration mode, but only the corresponding amplitude. In the present application, although dealing with output-only data, the eigenvectors have not been scaled since damage is localized and assessed from a qualitative point of view. The relationship between qualitative and quantitative damage measures has not been addressed yet. The results of the spectral damage 


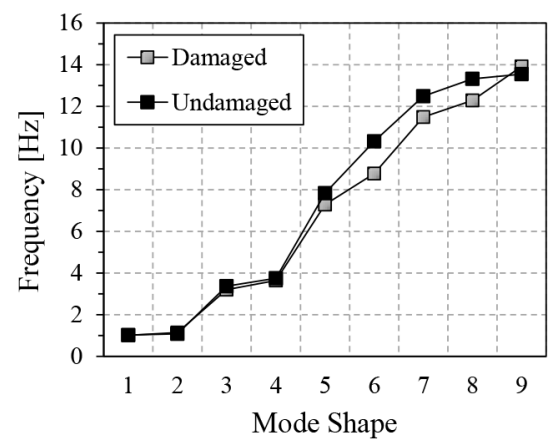

(a)

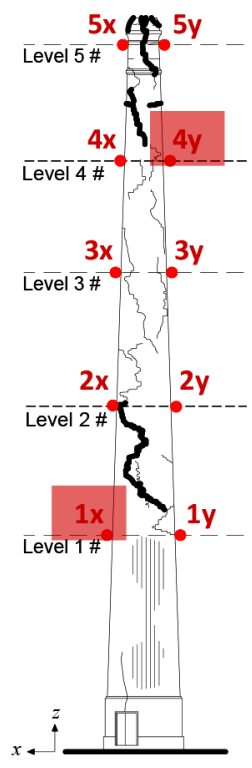

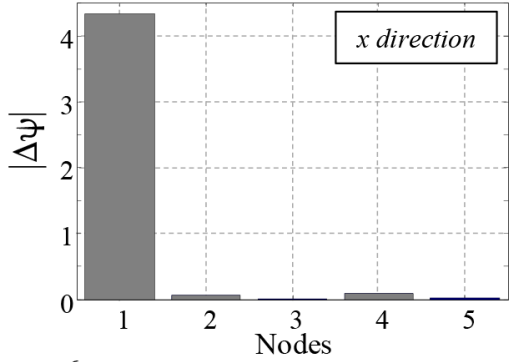

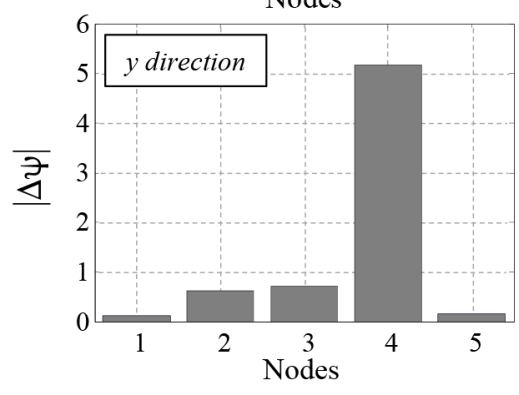

(b)

Figure 10. Results of the spectral damage analysis: (a) damage detection via the comparison of eigenvalues local maxima; (b) damage localization via the spectral index (the Arabic numbers indicate the investigated DOFs and the red squares mark the damage areas pinpointed by the spectral index).

analysis are displayed in Figure 10. The charts show clear-cut peaks at nodes 1 and 4 which are indeed the nodes closest to the parts of the chimney most affected by damage. Node 1 is located near the severe openings caused by the lightning and node 4 is situated where the disconnection of the upper part of the chimney originated. In terms of qualitative assessment, the size of the bars indicates that the damage in the upper part of the structure (position 4) is actually more severe than the damage registered at the bottom level (position 1). The reason leading to that is conceivably the slenderness of the chimney that, increasing upwards, makes the top part more vulnerable to damage than the bottom part.

\subsection{Comparison with other Damage Identification} Methods

To evaluate the performance and reliability of the spectrum-driven method, the obtained results are compared with the ones from other vibration-based damage identification methods applied to the same datasets. The methods selected for the task are the following: Unified Significance Indicator (USI) [Brincker et al. 1995]; Co-ordinate Modal Assurance Criterion (COMAC) [Ewins 2000]; Parameter Method (PM) [Dong et al. 1992]; Mode Shape Curvature Method (MSCM) [Kim et al. 2003]; Sum of all Curvature Errors method (SCE) [Kim et al. 2003]; Damage Index Method (DIM) [Stubbs et al. 1992]; Changes in Flexibility Matrix method (CFM) [Pandey and Biswas 1994]. The expressions used by each of this non-model-based methods to identify the damage are briefly indicated in Table 6 , specifying level of identification attempted and modal parameters required to compute the different indexes. The modal curvatures needed to compute some of the indexes are numerically derived from the mode shapes through the central difference theorem, whereas mass-scaled mode shapes are computed by applying a scaling factor to the known mode shapes [Aenlle et al. 2012], as follows:

$$
\alpha=\frac{1}{\sqrt{\varphi^{T} \cdot \mathrm{M} \cdot \varphi}}
$$

Note that the mass matrix $\mathbf{M}$ in Equation (11) is obtained based on the assumption of lumped masses in order to simplify and speed up the computation.

The first method applied is the USI, estimated for both frequencies and damping values by considering their respective shifts and standard deviations. The presence of damage is clearly detected by the significance indica-

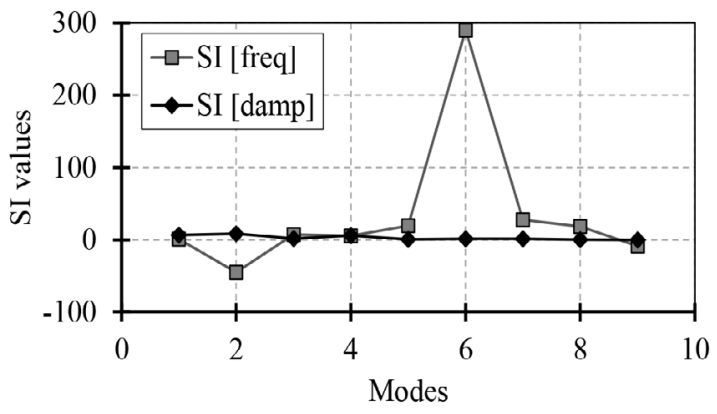

Figure 11. Damage detection by the Unified Significance Indicator. 


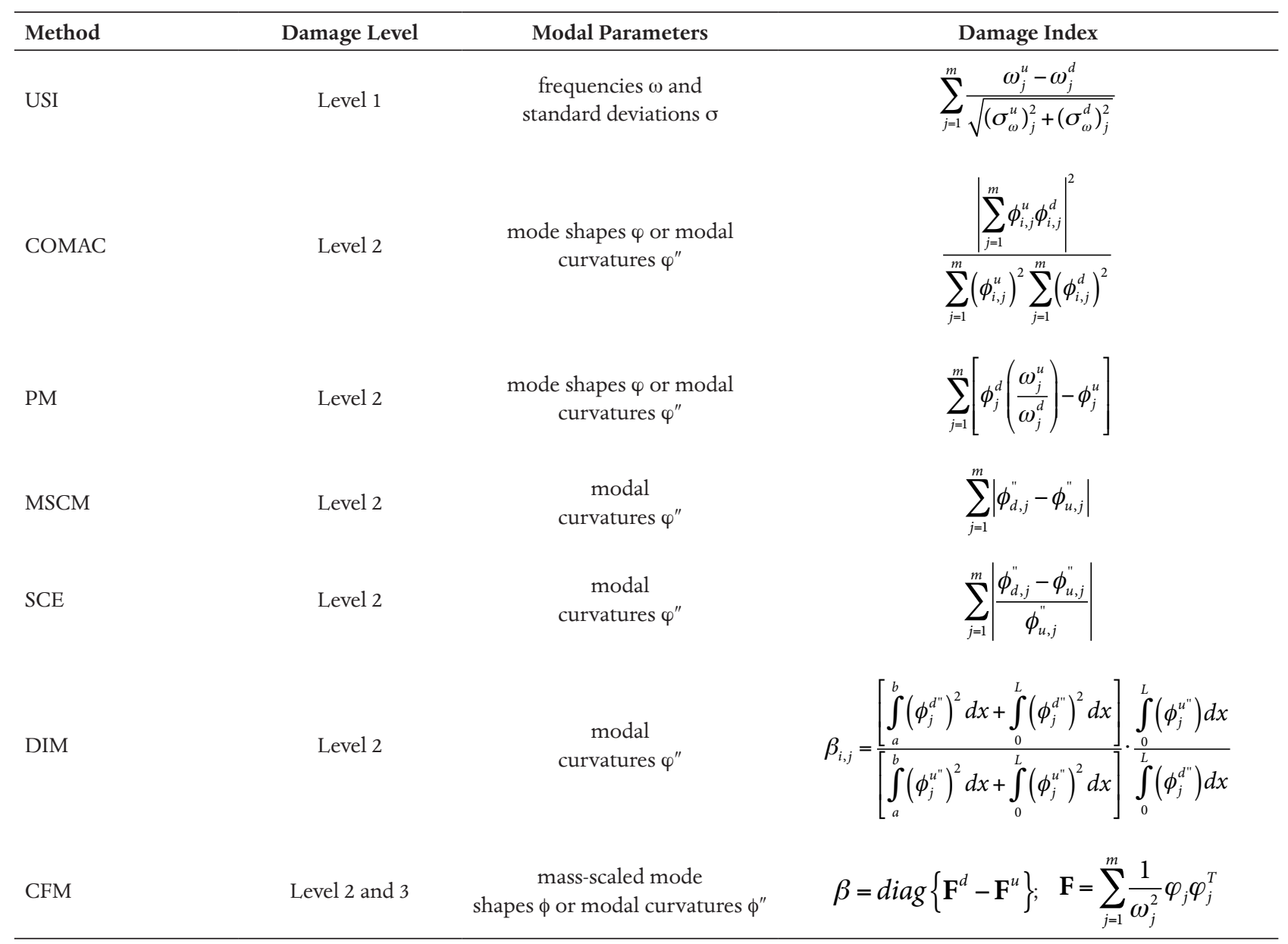

Table 6. List of selected damage identification methods.

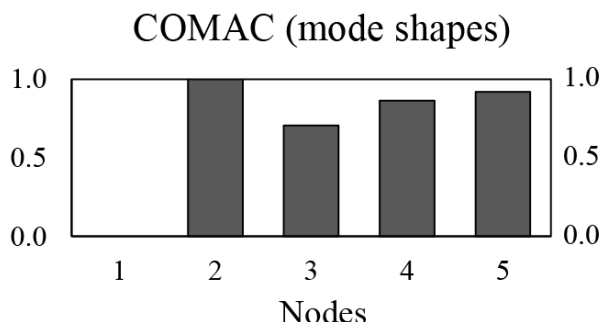

PM (mode shapes)

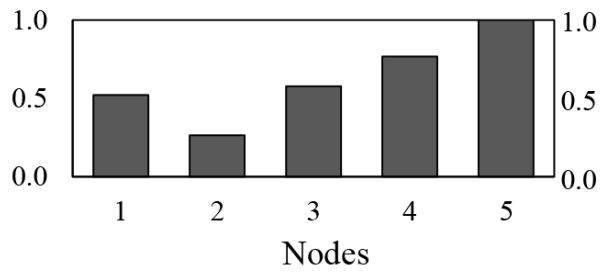

CFM (mode shapes)

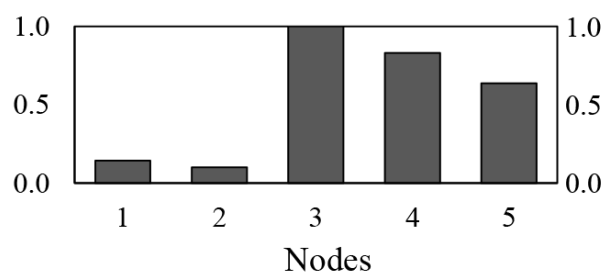

COMAC (curvatures)

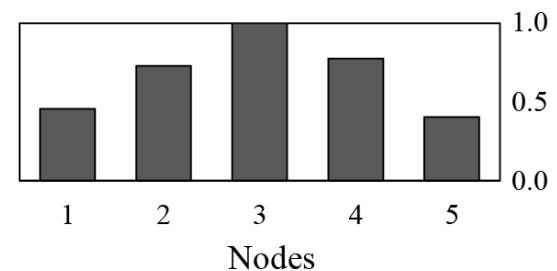

PM (curvatures)

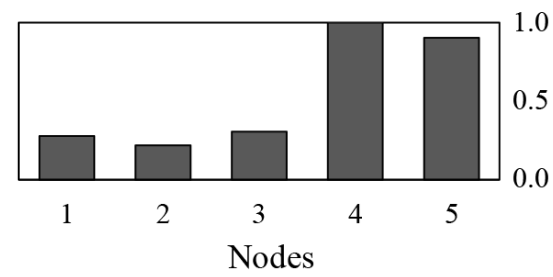

CFM (curvatures)
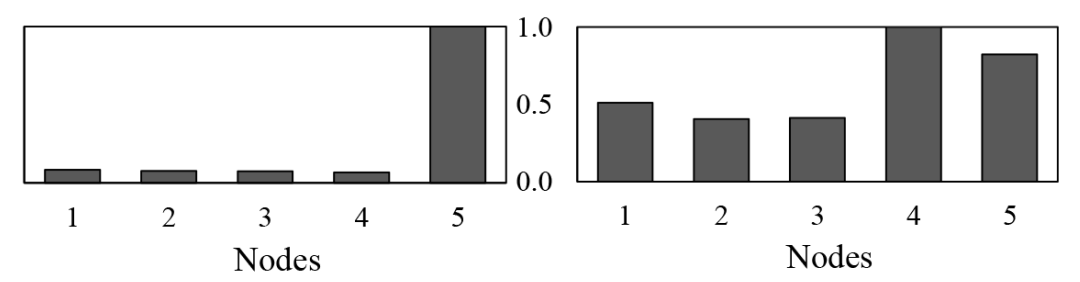

Figure 12. Damage localisation in $\mathrm{x}$ direction by selected modal-based methods. 
tors of frequency values, while the significance indicators of damping values do not give any warning (Figure 11). Being the USI a Level 1 method, no information about the possible damage location is provided.

Concerning the modal-based methods of Level 2 and 3 , all indexes are calculated taking into account the nodal response processes in $\mathrm{x}$ and $\mathrm{y}$ directions separately. Figure 12 shows the results obtained in $\mathrm{x}$ direction. Analysing the bar charts, it is highlighted that:

- the COMAC values for modal displacements indicate the presence of damage at position 1, whereas the COMAC for modal curvatures at positions 1 and 5 ;

- the SCE pinpoints the first node as possible damage location;

- the DIM catches the presence of damage at position 5 ;

- the PM for both modal displacements and curvatures identifies possible damage locations in the upper part of the chimney, namely at nodes 4 and 5, and so does the MSCM;

- the CFM for modal curvatures shows the damage at position 5, while the CFM for modal displacements at nodes 3,4 and 5 .

The results obtained in y direction are presented in Figure 13. In this case, the following remarks can be made:
- the CFM for modal displacements and the SCE show clear-cut peaks at position 4 , while the CFM for modal curvatures pinpoints node 5 as possible damage location;

- the PM for modal curvatures and the MSCM values locate damage in the upper part of the chimney at positions 4 and 5 ;

- the COMAC values for modal curvatures and the PM for modal displacements indicate the damage in three points, viz. 3, 4 and 5;

- the COMAC values for modal displacements identify the damage at position 3 , followed by nodes 4 and 1 ;

- the results from DIM locate damage at position 3. To make the comparison easier, the results obtained from all selected methods are summarised in Figure 14 with the exception of USI and COMAC. It is observed that the bulk of the methods circumscribe the damage to the upper part of chimney, whereas the spectral-based method and the SCE correctly identify the position of the most damaged areas.

Going into details, the COMAC provides quite good results (especially for the case of modal displacements) since it is based on the correlation between the measured DOFs of the two structural conditions. The dependence on local/nodal system

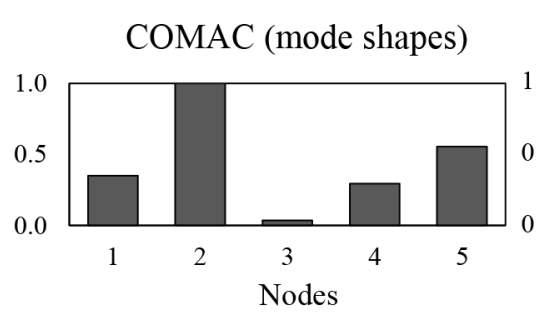

PM (mode shapes)

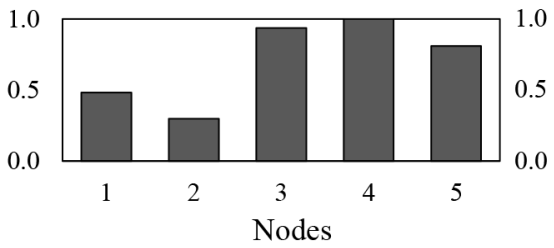

CFM (mode shapes)

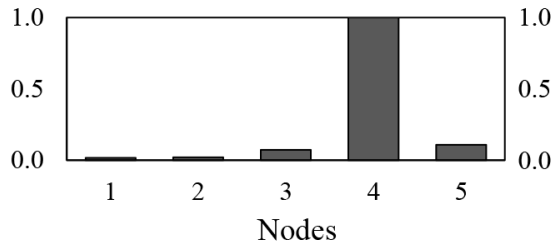

COMAC (curvatures)

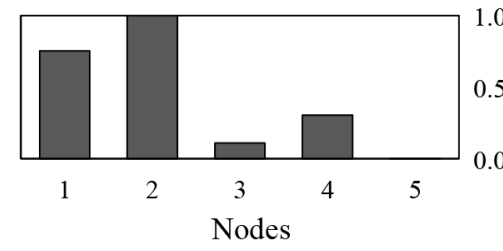

PM (curvatures)

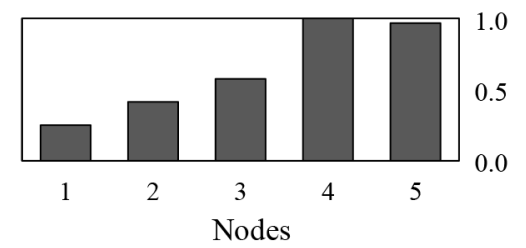

CFM (curvatures)

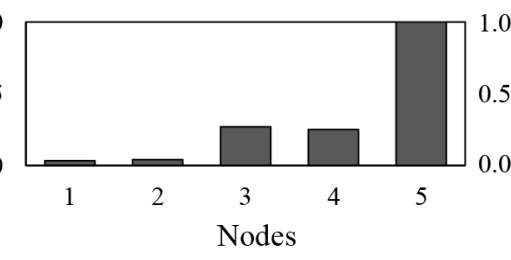

SCE

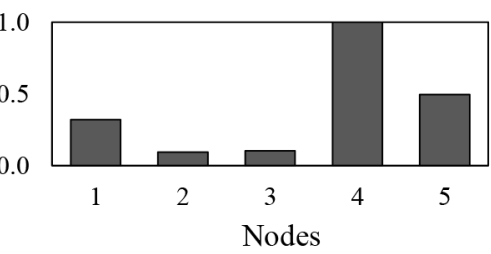

DIM

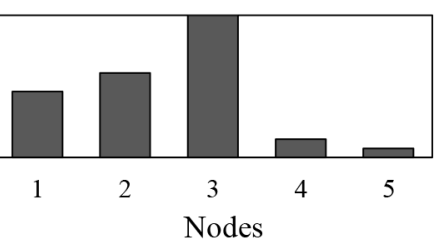

MSCM

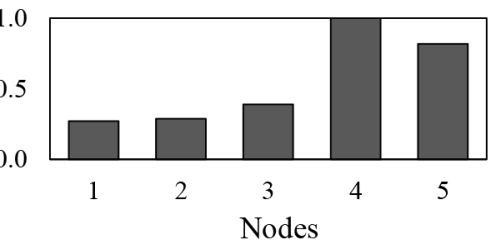

Figure 13. Damage localisation in y direction by selected modal-based methods. 


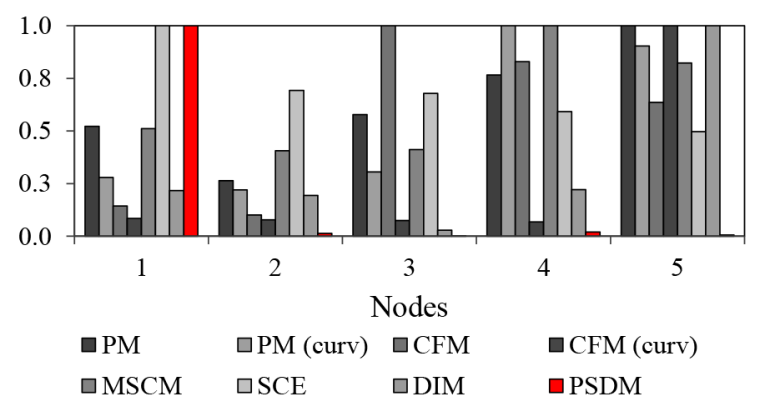

(a)

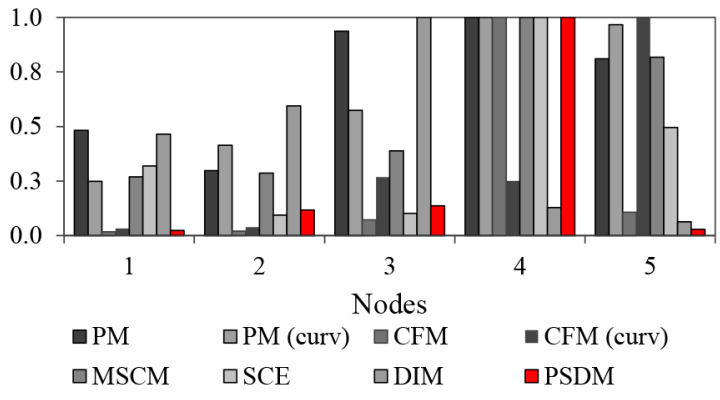

(b)

Figure 14. Comparison between all applied damage localisation methods: results in (a) $x$ direction and (b) $y$ direction.

coordinates is indeed of great help when seeking for local information as those related to the damage position. Regarding the PM, the failure in detecting the damage at position 1 is imputable to the small frequency shift between damaged and undamaged conditions for the lower modes, which are the ones dominating the dynamic response of the bottom part of the structure. Owing to that, the frequency ratio in the index formulation results almost negligible for the lower modes and does not provide accurate information about the damage at the bottom level. In what concerns the CFM, this method is able to pinpoint the damage, but limited to the upper part of the chimney. This is due to the inverse proportion of the flexibility matrix to the square of the modal frequencies, with consequent higher sensitivity of the index to changes in the lower-frequency modes. But, as shown previously, for the present case-study the vibration modes undergoing most changes in terms of frequencies are the higher modes. It is also remarked that the structural mass only suffered a slight variation between damaged and undamaged states, thus the difference in the scaling factors adopted to estimate mass-normalized mode shapes for both scenarios is very small and prevents from getting better results. Similarly, the MSCM does locate damage at positions 4 and 5 , but does not provide any information about the position of the two openings. This outcome plausibly depends on the formulation of the index itself as the MSCM is based on the difference between modal curvatures belonging to different damage scenarios. Since the curvature changes of the modes dominating the dynamic response of the lower part of the chimney are really minor, the MSCM is not able to locate the damage at the openings level (position 1). The failure of the DIM is likely due to the same reason.

The comparison with other damage indexes demonstrates the efficiency and accuracy of the spec- tral formulation in locating the damage of the chimney and highlights the potentiality of the method as a non-destructive tool for the damage identification of heritage structures.

\section{Seismic Vulnerability Assessment}

\subsection{Limit Equilibrium Analysis}

The effects of earthquakes on built environment can be significant, therefore it is imperative to investigate the vulnerability of structures under seismic loading. Generally speaking, structural vulnerability assessment entails the analysis of the seismic capacity of a structure located in an earthquake-prone area in order to check its robustness to withstand a certain earthquake magnitude. As for historic masonry structures, it is widely known that these systems are particularly vulnerable to seismic actions and often experience partial collapses due to the loss of equilibrium of portions of structure that are not able to resist to earthquake-induced loading and behave as rigid bodies [Giuffrè, A. Letture sulla meccanica delle murature storiche - Kappa, 1991, Lourenço et al. 2009, D’Ayala and Speranza 2003]. To mitigate the risk of damage of built cultural heritage, standards recommend to evaluate their vulnerability level against seismic forces by analysing the most meaningful collapse mechanisms of the system. For the present case-study structure, this has been done through a limit equilibrium analysis in conformity with the kinematic approach provided by the Italian Technical Regulations for Construction [DM 14.01.2008]. The codified procedure relies on the assumption of a no-tension masonry material with infinite compressive strength and no sliding between units. The position of the disconnections between the rigid blocks composing the kinematic chain, viz. the position of the hinges about which the collapse mechanism develops, has been fixed based on the crack pattern inspected in situ before the structural interven- 

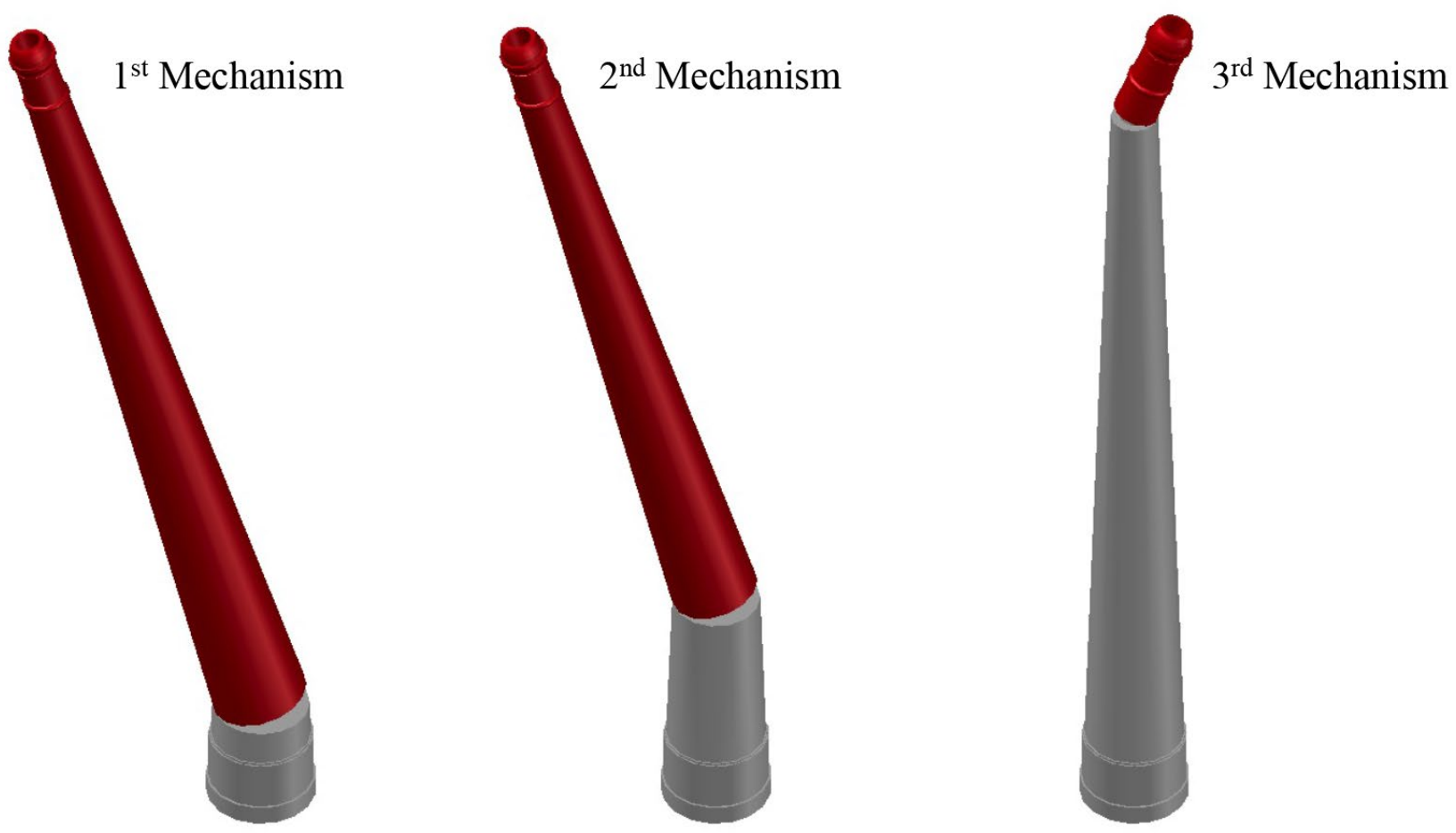

Figure 15. Overturning mechanisms considered for the limit equilibrium analysis.

tion. Figure 15 illustrates the three local mechanisms considered in the limit kinematic analysis, besides the global collapse mechanism. For each case, the horizontal loads multiplier $\alpha_{0}$ that activates the damage mechanism is determined (Virtual Work Principle). Then, the maximum values of spectral acceleration $a_{0}^{*}$ corresponding to the collapse of each kinematic chain are computed along with the relevant spectral displacements $d_{0}^{*}$, allowing to determine the capacity curve of the system case-by-case and to evaluate its ultimate displacement capacity $d_{u}^{*}$. Table 7 presents the results obtained from the limit equilibrium analysis. The lowest seismic capacity is associated with both the global mechanism and the first identified local mechanism, reading values of maximum spectral acceleration equal to $0.107 \mathrm{~g}$ and $0.105 \mathrm{~g}$, respectively, while the equivalent spectral displacements correspond to $0.59 \mathrm{~m}$ and $0.54 \mathrm{~m}$. The highest resistance is obtained for the third collapse mechanism, which features values of $a_{0}^{*}$ and $d_{0}^{*}$ equal to $0.347 \mathrm{~g}$ and $0.29 \mathrm{~m}$.

\subsection{Assessment of Seismic Capacity versus Seismic Demand}

In order to assess the seismic vulnerability of the chimney, the structural capacity is compared with the relevant seismic demand $\Delta$. Since the system was already damaged, this safety verification is carried out only with respect to the Ultimate Limit State (ULS). According to the Italian regulations [DM 14.01.2008], two criteria can be adopted to verify the fulfilment of the ULS for local collapse mechanisms. The first crite- rion consists in the simplified verification with $\mathrm{q}$ factor (linear kinematic analysis) which is fulfilled if the spectral acceleration $a_{0}^{*}$ responsible for the activation of the mechanism satisfies the following inequality:

$$
a_{0}^{*} \geq \frac{a_{g} \cdot S}{q}
$$

where $a_{g}$ is the peak ground acceleration, $S$ stands for soil coefficient, and q represents the behaviour factor accounting for the energy dissipation capacity of the structure. Yet, if the mechanism involves a part of the structure located at a certain height from the ground level, one should also account for the amplification of acceleration at the level where the kinematic mechanism develops. Therefore, beyond Equation (12), the following verification must be carried out:

$$
a_{0}^{*} \geq \frac{S_{e}\left(T_{1}\right) \cdot \Psi(Z) \cdot \gamma}{q}
$$

in which: $S_{e}\left(T_{1}\right)$ is the elastic response spectrum, $T_{1}$ indicates the first vibration period of the structure in the considered direction, $\Psi(\mathrm{Z})$ is the first vibration mode of the structure in the considered direction normalised with respect to the total height $\mathrm{H}$ of the system, $\mathrm{Z}$ indicates the height of the centroid of the seismic masses generating the kinematic mechanism, $\gamma$ is the modal participation coefficient and $\mathrm{q}$ is defined as above.

The second criterion consists in the comparison between the ultimate displacement capacity $d_{u}^{*}$ of the kinematic mechanism and the displacement demand of the earthquake $\Delta_{d}\left(T_{s}\right)$ (non-linear kinematic analy- 


\begin{tabular}{lccccc}
\hline Collapse Mechanism & $\alpha_{0}^{*}$ & $M^{*}\left(\mathbf{1 0}^{3} \mathbf{k g}\right)$ & $a_{0}^{*}(\mathbf{g})$ & $d_{0}^{*}(\mathbf{m})$ & $d_{u}^{*}(\mathbf{m})$ \\
\hline Global & 0.129 & 92.66 & 0.107 & 0.59 & 0.23 \\
$1^{\text {st }}$ Local & 0.126 & 71.59 & 0.105 & 0.54 & 0.22 \\
$2^{\text {nd }}$ Local & 0.134 & 51.67 & 0.112 & 0.54 & 0.21 \\
$3^{\text {rd }}$ Local & 0.416 & 3.35 & 0.347 & 0.29 & 0.12 \\
\hline
\end{tabular}

Table 7. Parameters adopted in the limit equilibrium analysis.

( $\alpha_{0}^{*}$ is the load multiplier; $M^{\star}$ is the participating mass; $a_{0}^{*}$ is the spectral acceleration; $d_{0}^{*}$ is the spectral displacement; and $d_{u}^{*}$ is the ultimate displacement).

\begin{tabular}{|c|c|c|c|c|c|c|c|}
\hline Scenario & Mechanism & $a_{0}^{*}(\mathrm{~g})$ & $\Delta_{a}(\mathrm{~g})$ & $\mathrm{SF}_{a}$ & $d_{u}^{*}(\mathrm{~m})$ & $\Delta_{d}(\mathrm{~m})$ & $\mathrm{SF}_{d}$ \\
\hline \multirow{4}{*}{$\begin{array}{l}\text { Seismic } \\
\text { Action } 1\end{array}$} & Global & 0.107 & 0.018 & 6.03 & 0.23 & 0.027 & 8.82 \\
\hline & $1^{\text {st }}$ Local & 0.105 & 0.015 & 6.92 & 0.216 & 0.023 & 9.41 \\
\hline & $2^{\text {nd }}$ Local & 0.112 & 0.018 & 6.26 & 0.215 & 0.027 & 8.06 \\
\hline & $3^{\text {rd }}$ Local & 0.347 & 0.029 & 11.98 & 0.116 & 0.059 & 1.97 \\
\hline \multirow{4}{*}{$\begin{array}{l}\text { Seismic } \\
\text { Action } 2\end{array}$} & Global & 0.107 & 0.041 & 2.64 & 0.23 & 0.025 & 9.26 \\
\hline & $1^{\text {st }}$ Local & 0.105 & 0.015 & 7.27 & 0.216 & 0.022 & 9.88 \\
\hline & $2^{\text {nd }}$ Local & 0.112 & 0.017 & 6.58 & 0.215 & 0.025 & 8.47 \\
\hline & $3^{\text {rd }}$ Local & 0.347 & 0.028 & 12.58 & 0.116 & 0.056 & 2.07 \\
\hline
\end{tabular}

Table 8. Comparison between seismic capacity and seismic demand.

( $\Delta_{a}$ is the acceleration seismic demand; $\Delta_{d}$ is the displacement seismic demand; and SF is the safety factor).

sis). The verification for this ULS implies the fulfilment of the following requirement:

$$
d_{u}^{*} \geq S_{D E}\left(T_{S}\right)
$$

in which $S_{D e}$ is the elastic displacement response spectrum and Ts stands for secant period. Again, when the mechanism involves a part of the structure situated at a certain distance from the ground level, the requirement in Equation (14) must be complemented with the verification below:

$$
d_{u}^{*} \geq S_{D E}\left(T_{1}\right) \cdot \Psi(Z) \cdot \gamma \frac{\left(\frac{T_{S}}{T_{1}}\right)^{2}}{\sqrt{\left(1-\frac{T_{S}}{T_{1}}\right)^{2}+0.02 \frac{T_{S}}{T_{1}}}}
$$

where $S_{D e}, T_{s}, T_{s}, \Psi(Z)$ and $\gamma$ are defined as above.

According to the Portuguese seismic zonation, Guimarães is located in a zone characterised by a site peak ground acceleration on rock $a_{g}=0.036 \mathrm{~g}$ for seismic action 1 (earthquakes with offshore epicentres) and $a_{g}=0.082 \mathrm{~g}$ for seismic action 2 (earthquakes with inland epicentres). Notwithstanding the low seismicity level, the vulnerability of the chimney is assessed for either seismic scenario, defining the two corresponding response spectra as specified by the Portuguese National Annexes of Eurocode 8 [EN 1998-1:2004 + AC:2009 Pt, Eurocode 8]. A soil stratigraphic profile of type $A$ and a site coefficient $S$ equal to 1 are assumed for the spectra estimation. The results are summarised in Table 8 where the safety factor SF (capacity over demand ratio) obtained for each damage mechanism is also indicated. The seismic capacity of the historic chimney is found to be much greater than the relevant seismic demand, being the lowest safety factor equal to 1.97 .

\section{Conclusions}

The paper has presented the study of a historic masonry chimney located in Guimarães, a small town in the North of Portugal characterised by a low seismicity level. The structure was struck by lightning with consequent aggravation of its poor conditions. Although the extension and severity of damage were remarkable, the changes in the modal properties of the system before and after the restoration works were little. This provided a significant challenge for the damage identification, but the proposed spectrum-driven approach proved to be successful in detecting, locating and qualitatively assessing the damage of the structure analysed. Despite the difficulties of the present case study and the limited modal data available, the results showed a good agreement with the experimental evidence, while most of the conventional modal-based methods applied to the same datasets resulted to be less accurate and reliable. Advantages and drawbacks of each technique have been extensively discussed in the paper. Lastly, once the most vulnerable parts of the chimney have been identified, a limit analysis was carried out in order to quantify the structural capacity over the seismic demand and to assess the seismic performance of the historic structure. 
The work has shown that a direct correlation exists between dynamic characterization, damage identification and seismic vulnerability assessment. These three aspects need to be addressed properly in order to mitigate the risk of damage of heritage structures located in areas with high seismic activity. Reliable damage identification methods that can be easily implemented in the engineering practice for supervised SHM are therefore fundamental.

\section{References}

Abdel Wahab, M. M. and G. De Roeck (1999). Damage detection in bridges using modal curvatures: application to a real damage scenario. Journal of Sound and Vibration, 226(2): 217-235.

Aenlle, M. L., R. Brincker, F. Pelayo and A. F. Canteli (2012). On exact and approximated formulations for scaling-mode shapes in operational modal analysis by mass and stiffness change. Journal of Sound and Vibration, 331(3): 622-637.

Brincker, R., P. Andersen, P. H. Kirkegaard and J. P. Ulfkjær (1995). Damage detection in laboratory concrete beams. In Proceedings of the 13th International Modal Analysis Conference. Bethel, Connecticut: Society for Experimental Mechanics, 1, 668-674.

Brincker, R., L. Zhang and P. Andersen (2001). Modal Identification of output-only systems using frequency domain decomposition. Smart Materials and Structures, 10: 441-445.

Cantieni, R. (2005). Experimental methods used in system identification of civil engineering structures. In: Proceedings of the 1st International Operational Modal Analysis Conference, Copenhagen, 249-260.

Carden, E. and P. Fanning (2004). Vibration based condition monitoring: a review. Structural Health Monitoring, 3(4): 355-377.

D'Ayala, D. and E. Speranza (2003). Definition of Collapse Mechanisms and Seismic Vulnerability of Historic Masonry Buildings. Earthquake Spectra, 19(3): 479-509.

Di Paola, M. (1998). Digital simulation of wind field velocity. Journal of Wind Engineering and Industrial Aerodynamics, 74-76: 91-109.

Doebling, S., C. Farrar and M. Prime (1998). A summary review of vibration-based damage identification methods. Shock and vibration digest, 30(2): 91-105.

Doebling, S., C. Farrar, M. Prime and D. Shevitz (1996). Damage identification and health monitoring of structural and mechanical systems from changes in their vibration characteristics: a literature review. Los
Alamos National Laboratory, NM, 132.

De Matteis, G., F. Campitiello, M.G. Masciotta and M. Vasta (2012). Damage identification of masonry structures under seismic excitation. In Computational Methods in Stochastic Dynamics, vol.2, Springer Netherlands, ISBN: 978-94-007-5133-0, 345-356.

Dong, C., P. Q. Zhang, W. Q. Feng and T. C. Huang (1994). The sensitivity study of the modal parameters of a cracked beam. In Proceedings of the 12th International Modal Analysis Conference. Honolulu, Hawaii, 98-104.

DM 14.01.2008, New technical regulations for construction (NTC 2008) and related explanatory Circular no. 617 of 02.02 .2009 (in Italian).

EN 1998-1:2004 + AC:2009 Pt, Eurocode 8: Design of structures for earthquake resistance, Part 1: General rules, seismic action and rules for building (in Portuguese), Brussels, 2004.

Ewins, D. J. (2000). Modal testing: theory, practice and application. 2nd edition, Research Studies Press LDT.

Fan W. and P. Qiao (2010). Vibration-based damage identification methods: a review and comparative study. Structural Health Monitoring, 10(1): 83-111.

Fang, S.-E. and R. Perera (2009). Power mode shapes for early damage detection in linear structures. Journal of Sound and Vibration, 324(1-2): 40-56.

Gentile, A., and A. Messina (2003). On the continuous wavelet transforms applied to discrete vibrational data for detecting open cracks in damaged beams. International Journal of Solids and Structures, 40(2): 295-315.

Gentile, C., and A. Saisi (2007). Ambient vibration testing of historic masonry towers for structural identification and damage assessment. Construction and Building Materials, 21(6): 1311-1321.

Giuffrè, A. Letture sulla meccanica delle murature storiche, Kappa, 1991.

Kim, J. T. and N. Stubbs (2003). Crack detection in beamtype structures using frequency data. Journal of Sound and Vibration, 259: 145-160.

Liberatore, S. and G. P. Carman (2004). Power spectral density analysis for damage identification and location. Journal of Sound and Vibration, 274(3-5): 761-776.

Lourenço, P.B., N. Mendes and R. Marques (2009). Earthquake assessment of masonry structures: review and applications. In Trends in Civil and Structural Engineering Computing. Saxe-Coburg Publications, Stirlingshire, Scotland, chapter 4, 77-101.

MATLAB (2010). MATLAB User's Manual, Release 7.10.0. The Math Works, USA. 
Masciotta MG (2015) Damage identification based on spectral output signals. $\mathrm{PhD}$ Thesis, University of Minho, Portugal - University “G. d'Annunzio”, Italy.

Masciotta, M. G., L. F. Ramos, P. B. Lourenço and M. Vasta (2017). Spectral algorithm for non-destructive damage localisation: Application to an ancient masonry arch model. Mechanical Systems and Signal Processing, 84 (Part A): 286-307.

Masciotta, M. G., L. F. Ramos, P. B. Lourenço, M. Vasta and G. De Roeck (2016). A Spectrum-driven damage identification technique: application and validation through the numerical simulation of the Z24 Bridge. Mechanical Systems and Signal Processing, 70-71: 578-600.

Masciotta, M.G., L. F. Ramos, P. B. Lourenço and M. Vasta (2014). Structural Monitoring and Damage Identification on a Masonry Chimney by a Spectral-based Identification Technique. In Proceedings of the 9th International Conference on Structural Dynamics. Porto, Portugal.

Pandey, A. K., M. Biswas and M. M. Samman (1991). Damage detection from changes in curvature mode shapes. Journal of Sound and Vibration, 145(2): 321332.

Pandey, A. K. and M. Biswas (1994). Damage detection in structures using changes in flexibility. Journal of Sound and Vibration, 169(1): 3-17.

Peeters, B. and G. De Roeck (1999). Reference-based stochastic subspace identification for output-only modal analysis. Mechanical Systems and Signal Processing, 13(6): 855-878.

Peeters, B. and G. De Roeck (2001). One-year monitoring of the Z24-Bridge: environmental effects versus damage events. Earthquake Engineering and Structural Dynamics, 30: 149-171.

Ramos, L. F. (2007). Damage identification on masonry structures based on vibration signatures. PhD Thesis, University of Minho, Guimarães, Portugal.

Ramos, L. F., G. De Roeck, P. B. Lourenço, A. Campos-Costa (2010). Damage identification on arched masonry structures using ambient and random impact vibrations. Engineering Structures, 32(2010): $146-162$.

Ramos, L. F., M. G. Masciotta, P. B. Lourenço and M. Vasta (2013). SHM of a masonry chimney after a lightning accident. In: Structural Health Monitoring 2013, Proceedings of the 9th International Workshop on Structural Health Monitoring. Stanford, CA (USA), 1-2, 740-747.

Reynders, E., A. Teughels and G. De Roeck (2010). Finite element model updating and structural damage iden- tification using OMAX data. Mechanical Systems and Signal Processing, 24(2010): 1306-1323.

Reynders, E. and G. De Roeck (2009). Continuous vibration monitoring and progressive damage testing on the Z24 Bridge. In Encyclopedia of Structural Health Monitoring, chapter 126.

Sohn, H., C. Farrar and F. Hemez (2004). A review of structural health monitoring literature: 1996-2001. Los Alamos National Laboratory, NM.

Stubbs, N., J. T. Kim and K. Topole (1992). An efficient and robust algorithm for damage localization in offshore platforms. In Proceedings of ASCE 10th Structures Congress, 543-546.

SVS (2011). ARTeMIS Extractor Pro User's Manual, Release 5.4. Structural Vibration Solutions. Aalborg, Denmark.

Vakil-,Baghmisheh M. T., M. Peimani, M. H. Sadeghi and M. M. Ettefagh (2008). Crack detection in beamlike structures using genetic algorithms. Applied Soft Computing, 8(2): 1150-1160.

Yan, Y.J., L. Cheng, Z. Y. Wu and L. H. Yam (2007) Development in vibration-based structural damage detection technique. Mechanical Systems and Signal Processing, 21(5): 2198-2211.

\footnotetext{
*Corresponding author: Maria-Giovanna Masciotta University of Minho, Department of Civil Engineering, Campus de Azurém, 4800-058, Guimarães, Portugal email:mg.masciotta@gmail.com
}

2017 by Istituto Nazionale di Geofisica e Vulcanologia. All rights reserved 